\title{
Isotopic and elemental fractionation of solar wind implanted in the Genesis concentrator target characterized and quantified by noble gases
}

\author{
Veronika S. HEBER ${ }^{1,2^{*}}$, Roger C. WIENS ${ }^{3}$, Amy J. G. JUREWICZ ${ }^{4}$, Nadia VOGEL ${ }^{1}$, \\ Daniel B. REISENFELD ${ }^{5}$, Heinrich BAUR ${ }^{1}$, Kevin D. McKEEGAN ${ }^{2}$, Rainer WIELER ${ }^{1}$, \\ and Donald S. BURNETT ${ }^{6}$ \\ ${ }^{1}$ Institute for Geochemistry and Petrology, ETH Zurich, 8092 Zurich, Switzerland \\ ${ }^{2}$ Department of Earth and Space Sciences, UCLA, 595 Charles Young Drive East, Los Angeles, California 90095-1567, USA \\ ${ }^{3}$ Los Alamos National Laboratory, Los Alamos, New Mexico 87544, USA \\ ${ }^{4}$ Center for Meteorite Studies, Arizona State University, Tempe, Arizona 85287, USA \\ ${ }^{5}$ Department of Physics and Astronomy, University of Montana, Missoula, Montana 87544, USA \\ ${ }^{6}$ California Institute of Technology, Pasadena, California 91109, USA \\ *Corresponding author. E-mail: heber@ess.ucla.edu
}

(Received 22 July 2010; revision accepted 12 December 2010)

\begin{abstract}
We report concentrations and isotopic compositions of $\mathrm{He}, \mathrm{Ne}$, and Ar measured with high spatial resolution along a radial traverse of a silicon carbide $(\mathrm{SiC})$ quadrant of the Genesis mission concentrator target. The $\mathrm{Ne}$ isotopic composition maps instrumental fractionation as a function of radial position in the target: the maximum observed isotopic fractionation is approximately $33 \%$ per mass unit between the center and periphery. The $\mathrm{Ne}$ fluence is enhanced by a factor of 43 at the target center and decreases to 5.5 times at the periphery relative to the bulk solar wind fluence. Neon isotopic profiles measured along all four arms of the "gold cross" mount which held the quadrants in the concentrator target demonstrate that the concentrator target was symmetrically irradiated during operation as designed. We used implantation experiments of $\mathrm{Ne}$ into $\mathrm{SiC}$ and gold to quantify backscatter loss and isotopic fractionation and compared measurements with numerical simulations from the code "stopping and range of ions in matter." The ${ }^{20} \mathrm{Ne}$ fluence curve as a function of radial distance on the target may be used to construct concentration factors relative to bulk solar wind for accurate corrections for solar wind fluences of other light elements to be measured in the concentrator target. The $\mathrm{Ne}$ isotopic composition as a function of the radial distance in the $\mathrm{SiC}$ quadrant provides a correction for the instrumental mass-dependent isotopic fractionation by the concentrator and can be used to correct measured solar wind oxygen and nitrogen isotopic compositions to obtain bulk solar wind isotopic compositions.
\end{abstract}

\section{INTRODUCTION}

The accurate determination of the solar wind oxygen isotopic composition by laboratory analyses is the highest priority objective of NASA's Genesis mission (Burnett et al. 2003). The solar wind is a sample of the Sun's photosphere which serves as a proxy for solar nebula composition. By measuring the solar wind, we can better understand the origin and evolution of the different oxygen isotopic reservoirs sampled by early solar system materials (e.g., Clayton 2003). The measurement of the solar wind nitrogen isotopic composition is the second highest priority of the mission. The cause of the variability of nitrogen in solar system materials is not understood although these variations are significant $(>50 \%)$ in lunar soils and in some anomalous meteorites (e.g., Kerridge 1993; Hashizume et al. 2000).

To increase the fluence of oxygen and nitrogen, and presumably the analytical precision of the isotopic 


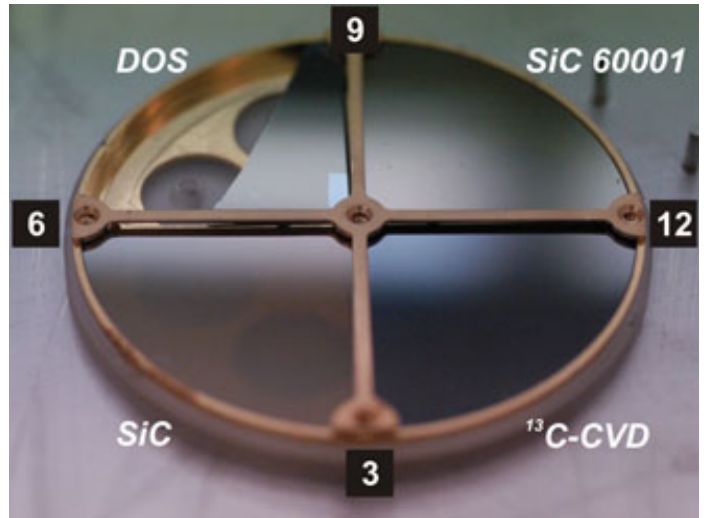

Fig. 1. Genesis concentrator target after return (cf. corresponding preflight image in Nordholt et al. 2003). The $\mathrm{Ne}$ isotopic composition was measured along a radial traverse on the SiC quadrant 60001. Numbers 3, 6, 9, and 12 represent the four gold cross arms analyzed in Heber et al. (2007) and in this work.

analyses, solar wind ions were concentrated onto a special target (Fig. 1) using an electrostatic mirror referred to as the Genesis concentrator (Nordholt et al. 2003; Wiens et al. 2003). The concentration process caused significant isotopic fractionation of the solar wind ions as function of the radial distance from the center of the target. To obtain the true isotopic composition of oxygen (McKeegan et al. 2010), nitrogen (Kallio et al. 2010; Marty et al. 2010) and possibly other elements in the solar wind, this instrumental mass fractionation has to be determined.

The isotopic mass fractionation of the concentrator was numerically modeled prior to launch using an ionoptical code that iteratively solves Laplace's equations for static electrostatic fields (SIMION) (Wiens et al. 2003). Heber et al. (2007) present the most recent summary of the postflight simulation and results. They measured the radial dependence of the mass fractionation by analyzing the ${ }^{20} \mathrm{Ne} /{ }^{22} \mathrm{Ne}$ isotopic composition along two arms of the gold-plated stainless steel cross (the "gold cross") used to mount the four individual concentrator target quadrants (Fig. 1). Originally, these data were to be used to correct for concentrator-induced mass fractionation of implanted solar wind oxygen and nitrogen ions in the silicon carbide ( $\mathrm{SiC}$ ) and diamond-like carbon on silicon (DOS) quadrants. However, the measured fractionation curve differed substantially from the modeled one (Heber et al. 2007). One potential reason for this difference is the rough surface of the gold cross and, thus, an unaccounted backscatter loss. SRIM (stopping and range of ions in matter; Ziegler 2004) simulations, on the other hand, that are included in the modeled data assume a perfect smooth surface. To resolve this issue, laboratory implantation experiments were performed to measure the isotopic fractionation related to backscatter losses. These data were compared with ratios numerically modeled using the SRIM code. As a result of the experiments (see below), we decided to measure the isotope fractionation curve of $\mathrm{Ne}$ directly on the same $\mathrm{SiC}$ quadrant on which solar wind oxygen and nitrogen had been previously analyzed. This allows for a direct fractionation correction of oxygen and nitrogen, one that is less reliant on modeled or measured differences of implantation- and backscatterinduced isotopic fractionations between light-mass $(\mathrm{SiC})$ and heavy-mass (gold) targets, respectively.

Here, we reiterate that the primary objective of the concentrator was to provide a high-fluence solar wind oxygen sample. It was built for optimal concentration of ions with mass over charge ratios $(\mathrm{m} / \mathrm{q})$ of $2-4.3$ (Wiens et al. 2003). This range corresponds to the masses of $4(\mathrm{He})$ to approximately $28(\mathrm{Si})$ at charge state distributions characteristic of bulk solar wind and should allow for the analysis of a spectrum of elements in the concentrator target beyond oxygen, nitrogen, and neon. To characterize the useful mass range of elements quantitatively captured by the concentrator, we analyzed the fluences and isotopic composition of $\mathrm{He}$ and $\mathrm{Ar}$ in the $\mathrm{SiC}$ quadrant.

In this work, (1) we present high spatial resolution measurements of the $\mathrm{Ne}$ isotopic composition and fluences along a radial traverse in the $\mathrm{SiC}$ quadrant of the concentrator target. The isotopic data are used to correct the oxygen and nitrogen isotopic composition measured in the concentrator target for concentratorinduced fractionation to obtain the true solar wind isotopic composition. (2) $\mathrm{We}$ present $\mathrm{He}$ and $\mathrm{Ar}$ isotopic compositions and fluences measured along the same traverse to characterize the mass range of elements concentrated in the target. We evaluate the measured fluences $(\mathrm{He}, \mathrm{Ne}$, and $\mathrm{Ar})$ and corresponding concentration factors relative to bulk solar wind with the goal of deducing solar wind fluences of other elements measured in the concentrator target, e.g., oxygen and nitrogen. (3) We present the $\mathrm{Ne}$ isotopic composition and fluences measured in all four arms of the gold cross to test for radial homogeneity of the irradiation throughout the entire concentrator target. (4) We performed ion implantation experiments to compare actual backscatter losses with those predicted by SRIM. These experiments compared isotopic fractionation for a rough (gold cross) and a smooth gold surface as well as $\mathrm{SiC}$ and also included irradiation at different angles of incidence. The resulting data are used to elucidate the observed discrepancy between measured and numerically modeled mass fractionation curves for the concentrator target. 


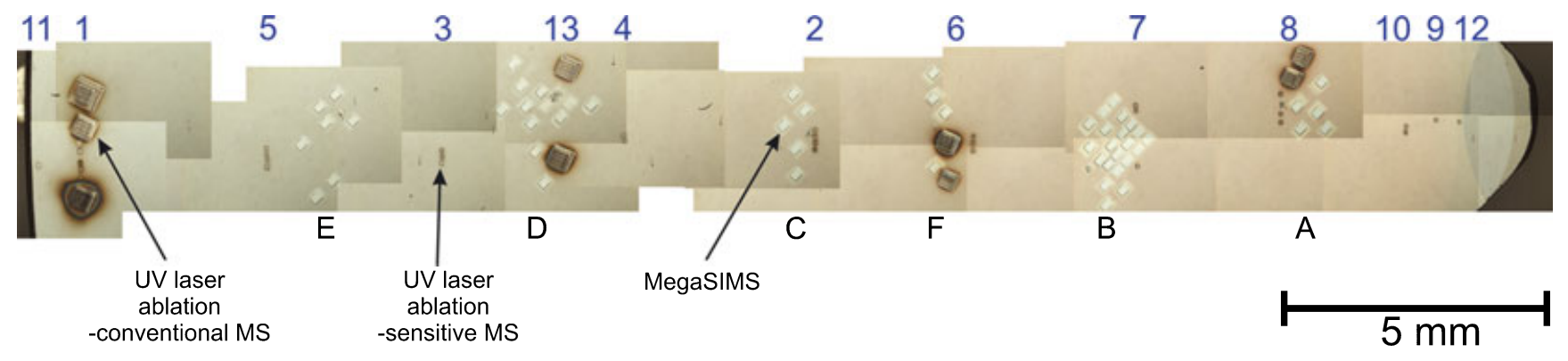

Fig. 2. Traverse analyzed in the SiC quadrant 60001. The center of the concentrator target is toward the right. The slightly darker sector at the right end of the $\mathrm{SiC}$ was underneath the gold cross during flight. Numbers (top) mark dark rectangular pits, the positions of noble gas analyses. Small pits indicate Ne analyses by the high-sensitivity mass spectrometer (MS); large pits indicate $\mathrm{He}$, Ne, and Ar analyses using a conventional MS (see the Noble Gas Analyses section). Letters (bottom) mark white, rectangular pits which are MegaSIMS oxygen and nitrogen analyses spots (Kallio et al. 2010; McKeegan et al. 2010).

\section{SAMPLES AND EXPERIMENTAL PROCEDURE}

\section{Genesis Concentrator Target Samples and Their Handling}

The Genesis concentrator target (Fig. 1) consists of four quadrants: two of epitaxially grown $\mathrm{SiC}$; one of an amorphous diamond-like carbon film physically deposited on a silicon substrate (abbreviated here as DOS); and one of ${ }^{13} \mathrm{C}$ diamond made using chemical vapor deposition (Jurewicz et al. 2003). The quadrants were held onto a base plate using an electroplated-gold stainless steel fitting (the "gold cross"; Nordholt et al. 2003). The radial distance from the center of the concentrator target to the outer edge of the gold cross or frame is $31 \mathrm{~mm}$, and the distance from the center to the inner and outer edges of each quadrant is 1.3 and $30 \mathrm{~mm}$, respectively.

At ETH Zürich, we analyzed $\mathrm{He}, \mathrm{Ne}$, and $\mathrm{Ar}$ along a single radial traverse in the $\mathrm{SiC}$ quadrant 60001 (Fig. 2) as well as $\mathrm{Ne}$ in all four arms of the gold cross (Table 1). Throughout this article we will compare the measured fluences and isotopic compositions in the $\mathrm{SiC}$ quadrant to bulk solar wind values obtained from the Genesis passive collectors on the $\mathrm{B} / \mathrm{C}$ arrays given in Heber et al. (2009a). The four arms of the gold cross (cut at NASA Johnson Space Center) were separately analyzed between 2006 and 2008. Preliminary data for the first two arms are given by Heber et al. (2007). The SiC quadrant was measured in January 2010, immediately after oxygen and initial nitrogen analyses in this target had been performed with the MegaSIMS at UCLA (Kallio et al. 2010; McKeegan et al. 2010). The gold cross arms were not cleaned prior to noble gas analysis. The SiC quadrant was cleaned with xylene at NASA Jet Propulsion Laboratory in the clean laboratory of D. A. Papanasstasiou prior to installation in the MegaSIMS. No further cleaning was performed prior to noble gas analysis. Light noble gases (including
Ar) are abundant in solar wind and negligible in terrestrial dust from the site of the hard landing of Genesis in Utah (Heber et al. 2009a).

\section{Laboratory Implantation Experiments}

Two laboratory implantation experiments were run to compare measured and SRIM-simulated backscatter losses. The first experiment investigated the influence of the surface roughness of gold on (1) the effective backscatter loss, (2) isotopic fractionation, and (3) the ability and accuracy of SRIM to correct for this loss. The second experiment compared the measured backscatter loss of $\mathrm{Ne}$ in $\mathrm{SiC}$ with those estimated using SRIM.

Accordingly, two sets of flight spare target materials were irradiated at Los Alamos National Laboratory, both with $1 \times 10^{14}{ }^{20} \mathrm{Ne}^{+} \mathrm{cm}^{-2}$ at $72 \mathrm{keV}$ and $1 \times 10^{1322} \mathrm{Ne}^{+} \mathrm{cm}^{-2}$ at $74 \mathrm{keV}$. These energies correspond to the mean implantation energies of solar wind ${ }^{20} \mathrm{Ne}$ and ${ }^{22} \mathrm{Ne}$, respectively, into the concentrator target during operation. The angle of incidence of the ion beam was normal to the implanted base plate $\left(=0^{\circ}\right.$, with a spreading angle of $\leq 0.85^{\circ}$ ). To simulate the effects of having solar wind implanted into the concentrator target at angles of $40^{\circ}-60^{\circ}$ during operation (Wiens et al. 2003), a portion of the materials was mounted on the wedges attached to the baseplate, which replicated angles of incidence of $45^{\circ}$ and $55^{\circ}$ off the normal (Fig. 3a). This procedure guaranteed an identical $\mathrm{Ne}$ current for all samples. Fluences were calculated from the measured sample area times the cosine of the respective angle of incidence to account for the smaller sample cross section at oblique incidence. Before analysis, all implanted materials were cleaned with acetone followed by deionized water. The first implanted set (Fig. 3a; Table 1) included the macroscopically rough gold cross material (Fig. 3b), the highly smooth, e-beam deposited gold on sapphire (AuoS), and DOS for reference. DOS-H, previously 


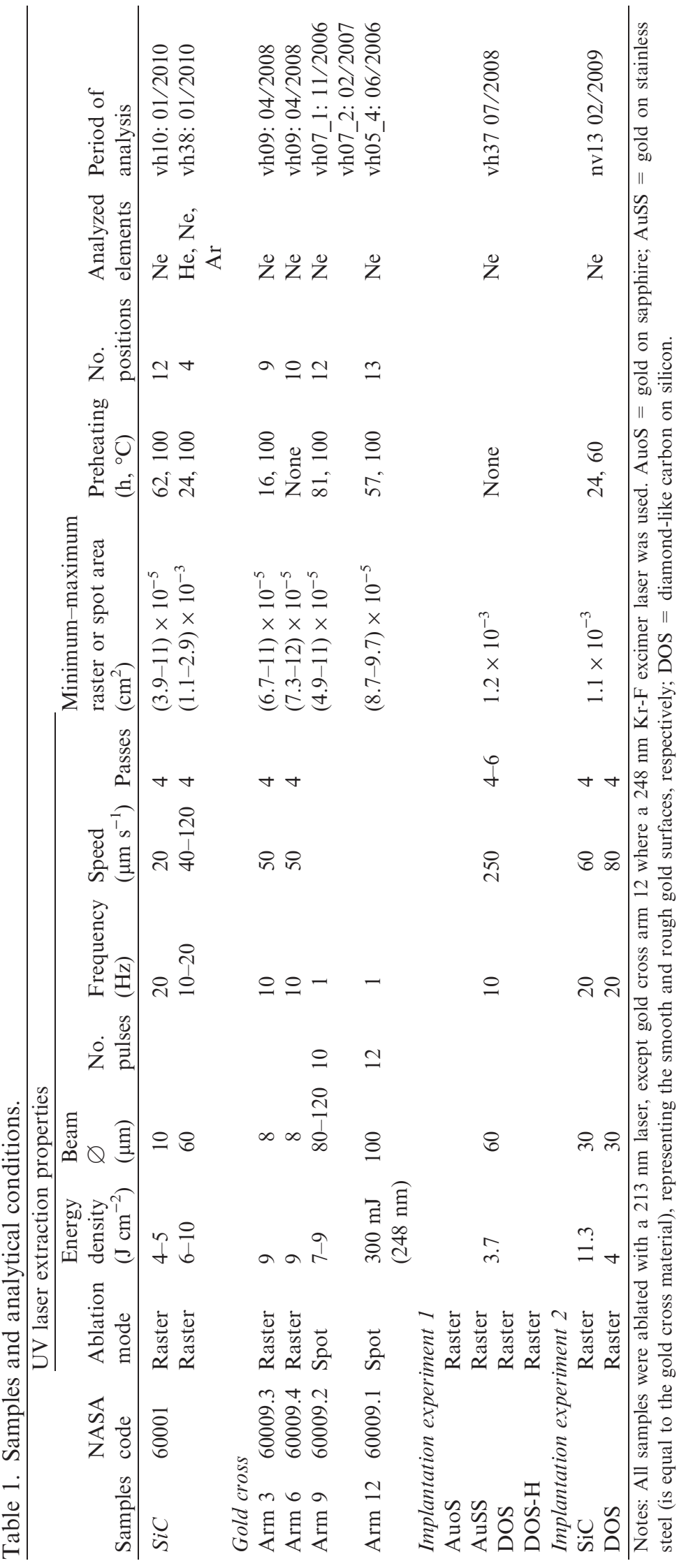




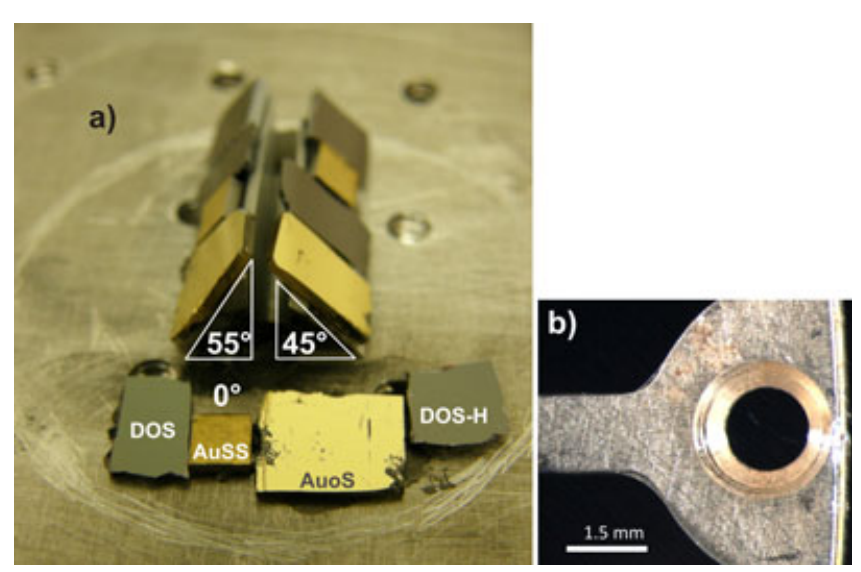

Fig. 3. a) Base plate for the first laboratory implantation experiment. The design allowed irradiation at several angles of incidence in one implantation run. The $\mathrm{Ne}$ beam incidence was normal to the base plate $\left(0^{\circ}\right)$, thus wedges mimic angles of incidence of $45^{\circ}$ and $55^{\circ}$ off the normal. b) Outer part of gold cross arm 3 shown here to illustrate the roughness of the as-flown gold cross surface.

irradiated with $1.8 \times 10^{16} \mathrm{H}^{+} \mathrm{cm}^{-2}$ at $6 \mathrm{keV}$, was also included to examine the influence of a high dose of implanted $\mathrm{H}$ on composition and concentration of implanted heavier ions. In the second implantation run, $\mathrm{SiC}$ and DOS were simultaneously irradiated. The expected amount of backscatter loss was determined by SRIM (Ziegler 2004) for ${ }^{20} \mathrm{Ne}$ and ${ }^{22} \mathrm{Ne}$ for each material and angle of incidence. For each simulation, $5 \times 10^{5}$ ions were used.

\section{Noble Gas Analyses}

Noble gases were extracted by UV laser ablation with a quintupled $\mathrm{Nd}$ :YAG laser $(213 \mathrm{~nm})$. Complete gas extraction was tested both on implant standards and by re-extractions. The major objective of this work is to provide a precise $\mathrm{Ne}$ isotopic composition curve of high spatial resolution along the concentrator target radius. Accordingly, $\mathrm{Ne}$ was analyzed with a highsensitivity mass spectrometer in all concentrator target samples (gold cross, $\mathrm{SiC}$ quadrant). Using this technique, only small raster areas or spot sizes $\left(\leq 1 \times 10^{-4} \mathrm{~cm}^{2}\right)$ were required, saving valuable sample material. This also allowed multiple sampling of 12 equally spaced positions located along a radial center line on the $\mathrm{SiC}$ quadrant. At nearly every radial position, two to five analyses were performed to attain higher precision (Fig. 2; Table 2). The gold cross arms were sampled with a similar spatial resolution. The $\mathrm{SiC}$ quadrant and the gold cross arms 3 and 6 were sampled by rastering the laser with a small spot size $(\sim 8 \mu \mathrm{m})$ over areas of approximately $80 \times 80 \mu \mathrm{m}^{2}$. Gold cross arms 9 and 12 were sampled with a laser spot size of approximately $100 \mu \mathrm{m}$ diameter without rastering (see Table 1 and Heber et al. 2009a for detailed ablation conditions). As will be shown below, the two techniques yield identical concentrations and isotopic ratios for the respective gold cross arms.

The high-sensitivity mass spectrometer, equipped with a molecular drag pump that almost quantitatively conveys the gas into the ion source (Baur 1999), is frequently used for low-concentration, terrestrial ${ }^{3} \mathrm{He}$ analyses. Therefore, the He fraction was not admitted to the mass spectrometer to avoid contamination by the comparatively large amounts of solar wind ${ }^{3} \mathrm{He}$. After gas release and cleaning, Ne was cryogenically trapped on a cold finger held at $12.7 \mathrm{~K}$ for $15 \mathrm{~min}$. Before $\mathrm{He}$ was pumped off, the small volume containing the $\mathrm{Ne}$ was separated from the extraction line to avoid any isotopic fractionation during pumping. Neon was released from the cryotrap at $50 \mathrm{~K}$ and admitted directly to the mass spectrometer. The complete separation of $\mathrm{Ne}$ from $\mathrm{He}$, as well as the complete release of $\mathrm{Ne}$ at $50 \mathrm{~K}$ was extensively tested by analysis of standard gases. In a few of the analyses, the rare isotope ${ }^{21} \mathrm{Ne}$ was included to verify that the isotopic fractionation induced by the concentrator is mass-dependent. However, over the course of these analyses we discovered a slight nonlinearity of the high-sensitivity mass spectrometer at very low counting rates, probably due to aging of the electron multiplier. We unfortunately had to reject the ${ }^{21} \mathrm{Ne}$ data obtained on this spectrometer and relied only on the fewer and somewhat less precise ${ }^{21} \mathrm{Ne}$ data obtained in the conventional spectrometer (discussed below) to evaluate the mass-dependency of the isotopic fractionation. The nonlinearity did not significantly affect the ${ }^{20} \mathrm{Ne}$ and ${ }^{22} \mathrm{Ne}$ analyses by the high-sensitivity spectrometer, although, based on analyses of variable amounts of standard gases, corrections of a few permil on ${ }^{20} \mathrm{Ne} /{ }^{22} \mathrm{Ne}$ were made on some data.

Helium and $\mathrm{Ar}$ isotopes in the $\mathrm{SiC}$ quadrant (Table 3) were analyzed with a conventional mass spectrometer since the high-sensitivity mass spectrometer is not suitable for noble gases heavier than $\mathrm{Ne}$ because of the high pump-out rate of the highsensitivity instrument. For completeness, and to include ${ }^{21} \mathrm{Ne}$, Ne was also measured during these runs. Due to the larger areas required (up to $400 \times 400 \mu \mathrm{m}^{2}$ per analysis), only four positions were sampled, distributed over the entire radius, with three of them analyzed in duplicate and position 1 in triplicate. This conventional mass spectrometer was also used to measure $\mathrm{Ne}$ in the laboratory-implanted materials. The analytical procedure is described in detail by Heber et al. (2009a).

All data are blank corrected. The average blank contribution is low and amounts to $\leq 0.5 \%$ for ${ }^{20,22} \mathrm{Ne}$ for the high-sensitivity mass spectrometer data and to 
Table 2. Ne fluences and the ${ }^{20} \mathrm{Ne} /{ }^{22} \mathrm{Ne}$ ratio measured along a traverse in the $\mathrm{SiC}$ quadrant.

\begin{tabular}{|c|c|c|c|c|c|c|c|}
\hline Sample & Position & $\begin{array}{l}\text { Distance from } \\
\text { center }(\mathrm{mm})\end{array}$ & $\begin{array}{l}\text { Area } \\
\left(10^{-5} \mathrm{~cm}^{2}\right)\end{array}$ & $\begin{array}{l}{ }^{20} \mathrm{Ne}\left(10^{12}\right. \\
\left.\text { atoms cm }{ }^{-2}\right)\end{array}$ & $\begin{array}{l}{ }^{20} \mathrm{Ne} \text { conc. } \\
\text { factor }\end{array}$ & ${ }^{20} \mathrm{Ne} /{ }^{22} \mathrm{Ne}$ & $\delta^{22} \mathrm{Ne}(\%)$ \\
\hline $\mathrm{VH}, 04,01$ & & & 5.71 & $6.62(1)$ & 5.56 & $14.03(3)$ & $-17.8 \pm 2.3$ \\
\hline $\mathrm{VH}, 04,02$ & & & 5.05 & $6.59(1)$ & 5.54 & $14.07(3)$ & $-21.1 \pm 2.1$ \\
\hline $\mathrm{VH}, 04,05$ & & & 5.25 & $6.38(1)$ & 5.35 & 14.09(3) & $-22.5 \pm 2.3$ \\
\hline $\mathrm{VH}, 04,26$ & & & 7.67 & $6.74(1)$ & 5.66 & $14.09(4)$ & $-22.0 \pm 2.9$ \\
\hline $\mathrm{VH}, 04,29$ & & & 10.98 & $6.64(1)$ & 5.57 & $14.06(3)$ & $-20.3 \pm 1.9$ \\
\hline Mean & 1 & 29.07 & & $6.59(13)$ & 5.54 & $14.07(3)$ & $-20.7 \pm 1.8$ \\
\hline $\mathrm{VH}, 04,04$ & & & 5.55 & 29.91(3) & 25.11 & $13.61(1)$ & $12.4 \pm 1.1$ \\
\hline $\mathrm{VH}, 04,06$ & & & 5.86 & 29.81(4) & 25.03 & $13.60(1)$ & $13.3 \pm 1.0$ \\
\hline $\mathrm{VH}, 04,27$ & & & 5.22 & $30.64(5)$ & 25.73 & $13.65(3)$ & $9.6 \pm 2.0$ \\
\hline $\mathrm{VH}, 04,33$ & & & 5.63 & $30.23(3)$ & 25.38 & $13.61(2)$ & $12.5 \pm 1.6$ \\
\hline Mean & 2 & 15.05 & & $30.15(37)$ & 25.31 & $13.61(2)$ & $11.9 \pm 1.6$ \\
\hline $\mathrm{VH}, 04,08$ & & & 5.55 & $14.56(2)$ & 12.22 & $13.81(2)$ & $-2.1 \pm 1.3$ \\
\hline $\mathrm{VH}, 04,11$ & & & 5.39 & $14.54(1)$ & 12.21 & $13.82(2)$ & $-2.9 \pm 1.5$ \\
\hline $\mathrm{VH}, 04,30$ & & & 7.25 & $14.49(2)$ & 12.17 & $13.92(2)$ & $-10.3 \pm 1.6$ \\
\hline Mean & 3 & 22.17 & & $14.53(4)$ & 12.20 & $13.85(6)$ & $-5.1 \pm 4.5$ \\
\hline $\mathrm{VH}, 04,09$ & & & 5.71 & 21.61(4) & 18.15 & $13.78(2)$ & $-0.22 \pm 1.77$ \\
\hline $\mathrm{VH}, 04,16$ & & & 5.62 & 21.34(3) & 17.92 & $13.78(2)$ & $-0.52 \pm 1.31$ \\
\hline Mean & 4 & 18.69 & & 21.47(19) & 18.03 & 13.78(2) & $-0.37 \pm 1.54$ \\
\hline $\mathrm{VH}, 04,10$ & & & 5.09 & $10.21(2)$ & 8.58 & $13.95(3)$ & $-12.6 \pm 2.4$ \\
\hline $\mathrm{VH}, 04,13$ & & & 4.84 & $9.92(1)$ & 8.33 & $13.94(4)$ & $-11.7 \pm 2.7$ \\
\hline $\mathrm{VH}, 04,20$ & & & 6.14 & $9.99(1)$ & 8.39 & $13.97(2)$ & $-13.5 \pm 1.3$ \\
\hline $\mathrm{VH}, 04,31$ & & & 9.79 & $9.94(1)$ & 8.35 & $13.97(3)$ & $-14.0 \pm 1.9$ \\
\hline Mean & 5 & 25.51 & & $10.02(13)$ & 8.41 & $13.96(1)$ & $-13.0 \pm 1.0$ \\
\hline $\mathrm{VH}, 04,12$ & & & 4.20 & $38.57(8)$ & 32.39 & $13.52(2)$ & $19.2 \pm 1.7$ \\
\hline $\mathrm{VH}, 04,14$ & & & 6.21 & $37.97(10)$ & 31.88 & $13.45(1)$ & $24.5 \pm 0.8$ \\
\hline $\mathrm{VH}, 04,17$ & & & 5.61 & $38.31(4)$ & 32.17 & $13.47(1)$ & $22.5 \pm 1.1$ \\
\hline Mean & 6 & 12.04 & & 38.29(30) & 32.15 & $13.48(4)$ & $22.1 \pm 2.7$ \\
\hline $\mathrm{VH}, 04,15$ & & & 4.54 & $44.16(4)$ & 37.08 & $13.32(2)$ & $34.1 \pm 1.2$ \\
\hline $\mathrm{VH}, 04,18$ & & & 5.38 & $44.33(2)$ & 37.22 & $13.34(1)$ & $32.5 \pm 0.8$ \\
\hline $\mathrm{VH}, 04,32$ & & & 5.71 & $44.57(2)$ & 37.42 & $13.34(1)$ & $32.5 \pm 1.0$ \\
\hline Mean & 7 & 8.94 & & $44.35(20)$ & 37.24 & $13.34(1)$ & $33.0 \pm 0.9$ \\
\hline $\mathrm{VH}, 04,19$ & & & 4.39 & $47.88(4)$ & 40.20 & $13.24(1)$ & $40.5 \pm 1.0$ \\
\hline $\mathrm{VH}, 04,28$ & & & 4.77 & $47.58(6)$ & 39.95 & $13.24(1)$ & $40.2 \pm 0.8$ \\
\hline $\mathrm{VH}, 04,34$ & & & 4.57 & $48.27(3)$ & 40.53 & $13.29(2)$ & $36.3 \pm 1.6$ \\
\hline Mean & 8 & 6.19 & & 47.91(35) & 40.23 & $13.26(3)$ & $39.0 \pm 2.3$ \\
\hline $\mathrm{VH}, 04,21$ & 9 & 3.22 & 4.26 & $43.18(3)$ & 36.25 & $13.18(1)$ & $45.2 \pm 0.9$ \\
\hline $\mathrm{VH}, 04,22$ & & & 4.27 & $51.79(3)$ & 43.49 & $13.23(1)$ & $41.5 \pm 0.6$ \\
\hline $\mathrm{VH}, 04,24$ & & & 5.23 & $51.28(3)$ & 43.05 & $13.20(1)$ & $43.7 \pm 0.8$ \\
\hline Mean & 10 & 3.80 & & $51.53(36)$ & 43.27 & 13.21(2) & $42.6 \pm 1.5$ \\
\hline $\mathrm{VH}, 04,23$ & 11 & 29.86 & 8.40 & $6.20(1)$ & 5.21 & 14.11(3) & $-23.5 \pm 2.3$ \\
\hline $\mathrm{VH}, 04,25$ & 12 & 2.78 & 3.92 & $31.83(3)$ & 26.72 & $13.21(2)$ & $42.7 \pm 1.2$ \\
\hline
\end{tabular}

Notes: Here and in Tables 3 and 8 errors given in parentheses are in units of the least significant digit. Single analysis errors and errors given for the mean are $1 \sigma$. Fluences do not contain uncertainties due to area determination $(\leq 2 \%)$.

The concentration (conc.) factor is relative to bulk solar wind ${ }^{20} \mathrm{Ne}$ fluence (Heber et al. 2009a) adjusted to the shorter exposure time of the concentrator target $(803.28$ versus 852.83 days $)\left(=1.19 \times 10^{12}\right.$ atoms $\left.\mathrm{cm}^{-2}\right)$.

Permil deviation $\left(\delta^{22} \mathrm{Ne} /{ }^{20} \mathrm{Ne}\right.$ ) is relative to bulk solar wind ${ }^{22} \mathrm{Ne} /{ }^{20} \mathrm{Ne}$ of $0.07258 \pm 0.00005$ (Heber et al. 2009a), its error reflects only the uncertainty of the measured data.

No duplicate measurements were carried out for positions 9, 11, and 12 (see text). 


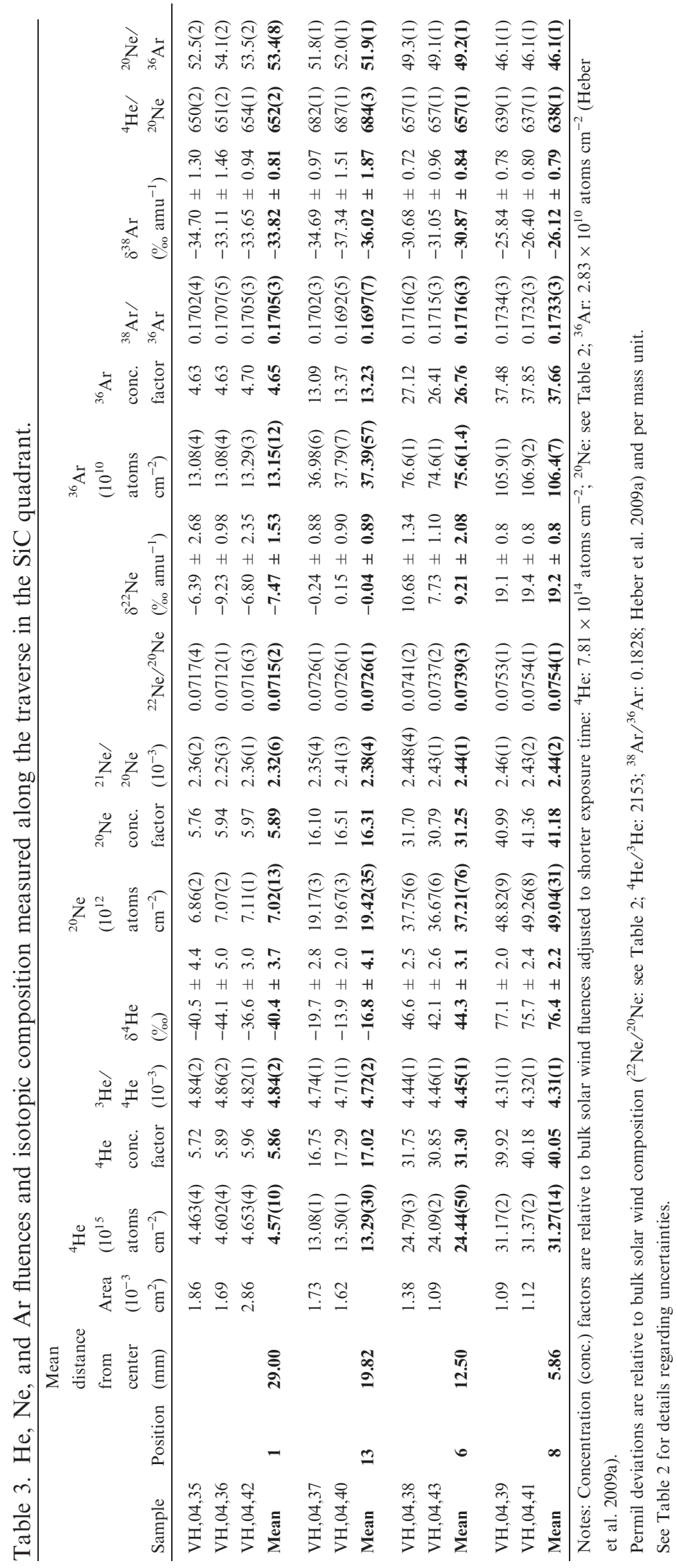


$<0.1 \%$ for all $\mathrm{He}$ and $\mathrm{Ne}$ isotopes analyzed with the conventional mass spectrometer. ${ }^{36,38} \mathrm{Ar}$ was corrected by assuming all ${ }^{40} \mathrm{Ar}$ is of terrestrial origin (as shown by Heber et al. 2009a). The respective average ${ }^{36,38} \mathrm{Ar}$ blank contribution was $0.8 \%$. Interference corrections were very low in both mass spectrometers, with an average contribution of ${ }^{40} \mathrm{Ar}^{2+}$ to sample ${ }^{20} \mathrm{Ne}^{+}$and of $\mathrm{CO}_{2}{ }^{2+}$ to ${ }^{22} \mathrm{Ne}^{+}$of $<0.001 \%$, respectively.

Uncertainties given throughout the article are $1 \sigma$. Errors in the fluences include statistical errors and errors due to blank correction and sensitivity variability. The error due to area determination is not included (see below). Errors of isotopic ratios include the statistical error and errors due to blank correction and mass discrimination. Errors in the arithmetic means given in this work are $1 \sigma$ standard deviations, or, if only two replicate analyses were carried out, the average of the single absolute errors, whichever quantity is higher.

The areas of all ablated pits were measured on calibrated photomicrographs. The uncertainty of the areas is $\leq 2 \%$ for the larger He-Ar $\left(\sim 400 \times 400 \mu \mathrm{m}^{2}\right)$ pits. The area of the much smaller $\mathrm{Ne}$ analysis pits $\left(80 \times 80 \mu \mathrm{m}^{2}\right)$ is more difficult to measure because ejecta partly covers the edges of the pits. The real extension of the edges was obtained for one small pit by comparing its ${ }^{20} \mathrm{Ne}$ fluence with the one from a large $\mathrm{He}-\mathrm{Ar}$ pit at the same radius. Afterwards, with the visual appearance of the pit edges familiar, all small pits were measured optically. The relative uncertainty of small pit areas is on average $1 \%$ and at maximum $4 \%$, determined by ${ }^{20} \mathrm{Ne}$ concentrations of replicate analyses (Tables 2 and 5). The distance of sampled areas from the center of the concentrator target was determined using calibrated photomicrographs for the $\mathrm{SiC}$ quadrant and the gold cross arms (Fig. 1).

\section{RESULTS}

\section{Neon Isotopic Compositions and Fluences Measured in the SiC Quadrant}

We first discuss the Ne data obtained by the highsensitivity mass spectrometer. Single and mean values of the ${ }^{20} \mathrm{Ne}$ fluences and the ${ }^{20} \mathrm{Ne} /{ }^{22} \mathrm{Ne}$ composition are given in Table 2. Mean ${ }^{20} \mathrm{Ne}$ fluences (Fig. 4) and ${ }^{20} \mathrm{Ne} /{ }^{22} \mathrm{Ne}$ ratios (Fig. 5) were fitted by an error-weighted sigmoidal Boltzmann function (Table 4) (except for the data at positions 9, 11, and 12; see below). This function interpolates the measured data very well, allowing a highaccuracy determination of the concentrator-induced isotopic fractionation and concentration factors for each position on the concentrator quadrants in the radial range accessible for solar wind sampling (i.e., $3.8 \mathrm{~mm}<r<29 \mathrm{~mm}$ ). Note that the slopes of the two

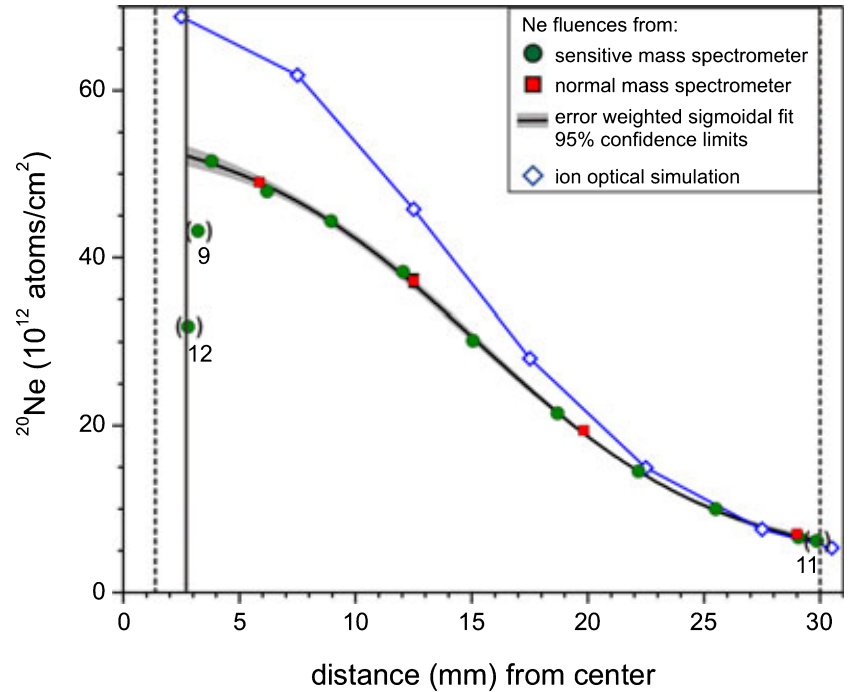

Fig. 4. Mean ${ }^{20} \mathrm{Ne}$ fluences measured along the traverse on the $\mathrm{SiC}$ quadrant are plotted as function of the distance from the concentrator target center. Measured ${ }^{20} \mathrm{Ne}$ fluences are shown for both data sets, from the high-sensitivity and the conventional mass spectrometer. Error bars of the measured data are within symbol size. Fit parameters are given in Table 4. The vertical lines mark the edges of the SiC quadrant (dashed) as well as the extent of the shadowed area (solid) (Fig. 2) caused by the gold cross structural support covering the center of the concentrator target (Fig. 1). The data at positions 9, 11, and 12 (not considered for the fit) showed that a $1 \mathrm{~mm}$ wide area adjacent to the totally shadowed area was partly shadowed. Fluences from a preliminary ion-optical simulation of the concentrator performance are about $30 \%$ higher in the inner part of the target $(r<\sim 10 \mathrm{~mm})$ than measured ones.

fits in Figs. 4 and 5 do not approach zero at the center of the target $(r=0)$. However, other fitting procedures taking this boundary condition into account fail to reproduce the measured data as precisely as the Boltzmann sigmoidal function we used.

\section{Ne Fluences}

Figure 4 shows the mean ${ }^{20} \mathrm{Ne}$ fluence plotted as function of the radial distance from the concentrator target center. All data plot on the sigmoidal fit for the entire length of the radius of the $\mathrm{SiC}$ quadrant. The $95 \%$ confidence limit of the fit to the ${ }^{20} \mathrm{Ne}$ fluences corresponds to an uncertainty of $1.6 \pm 0.7 \%$ within a radial range from 5 to $28 \mathrm{~mm}$. Also shown in Fig. 4 are the $\mathrm{Ne}$ fluences obtained from the conventional mass spectrometer. Concentration factors relative to bulk solar wind $\mathrm{Ne}$ fluence $\left(1.19 \times 10^{12}\right.$ atoms $\left.\mathrm{cm}^{-2}\right)$ are calculated by a slight adjustment for the somewhat shorter exposure of the concentrator target (803.28 days) relative to the $\mathrm{B} / \mathrm{C}$ arrays' passive collectors (852.83 days) with which the bulk solar wind fluence was obtained (Heber et al. 2009a). The 


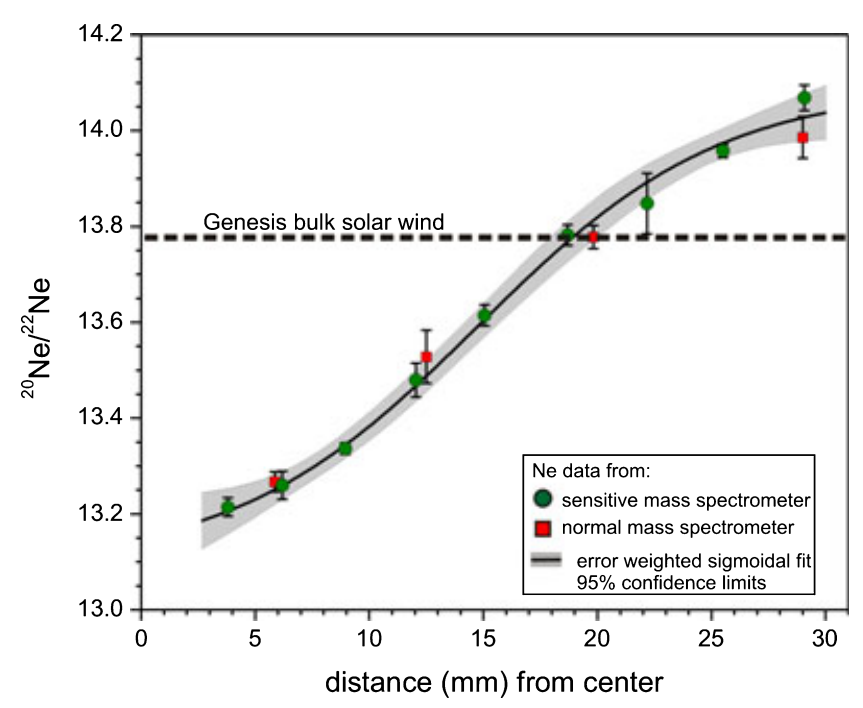

Fig. 5. Mean ${ }^{20} \mathrm{Ne} /{ }^{22} \mathrm{Ne}$ ratios measured along the traverse on the $\mathrm{SiC}$ quadrant are plotted as function of the distance from the concentrator target center. The horizontal dashed line shows the bulk solar wind ${ }^{20} \mathrm{Ne} /{ }^{22} \mathrm{Ne}$ ratio (Heber et al. 2009a). Both Ne isotope data sets agree within uncertainties. The sigmoidal curve fitted through the ${ }^{20} \mathrm{Ne} /{ }^{22} \mathrm{Ne}$ data from the high-sensitivity mass spectrometer serves as the isotopic fractionation curve to be applied to isotopic compositions of other elements measured in the concentrator target. Fit parameters are given in Table 4.

concentration factor is 5.54 at the periphery of the target (position 1, $29.07 \mathrm{~mm}$ ) and increases monotonically toward the center by almost eight times to a factor of 43.27 (position 10, $3.80 \mathrm{~mm}$ ). We also compare our measured fluences with preliminary SIMION 8.0 simulation results of the concentrator (Wiens et al. 2003; Heber et al. 2007; a complete description of the model calculations will be published separately). The output of the simulation is concentration factors as a function of the radial distance (Table 5), which, for Fig. 4, were multiplied by the Genesis bulk solar wind ${ }^{20} \mathrm{Ne}$ fluence adjusted for 803.28 days exposure $\left(1.19 \times 10^{12}\right.$ atoms $\left.\mathrm{cm}^{-2}\right)$. Backscatter-loss correction (based on SRIM simulations; Ziegler 2004) is included in the modeled data, so the modeled data are directly comparable to the measured data. The shapes of the modeled and measured ${ }^{20} \mathrm{Ne}$ fluence curves generally agree. However, the slope and thus the predicted absolute fluences differ. The model predicts a $30 \%$ higher fluence for the inner approximately $10 \mathrm{~mm}$, whereas modeled and measured curves agree within $\pm 5 \%$ in the outer range of the target $(22-28 \mathrm{~mm})$. The integrated fluence of the model is about $11 \%$ higher relative to the measured data. The ion simulations to date have not included losses due to grid scattering and losses due to passage of ions through grids at an angle. Both could account for the higher model fluence relative to the measured data.
Table 4. Fit parameter for the ${ }^{20} \mathrm{Ne} /{ }^{22} \mathrm{Ne}$ ratio and the ${ }^{20} \mathrm{Ne}$ fluence measured in the $\mathrm{SiC}$ quadrant.

\begin{tabular}{ll}
${ }^{20} \mathrm{Ne} /{ }^{22} \mathrm{Ne}$ & $\begin{array}{l}{ }^{20} \mathrm{Ne} \text { fluences } \\
(\text { atoms cm }\end{array}$ \\
\hline
\end{tabular}

Sigmoidal Boltzmann function, error weighted

$R^{2}=0.99739 \quad R^{2}=0.99981$

$y=A_{2}+\left(A_{1}-A_{2}\right) /\left(1+\mathrm{e}^{\left.\left(\left(x-x_{0}\right) / \mathrm{d} x\right)\right)}\right)$

$A_{1}=13.092 \pm 0.066 \quad A_{1}=(5.679 \pm 0.103) \times 10^{13}$

$A_{2}=14.092 \pm 0.049 \quad A_{2}=(2.939 \pm 0.438) \times 10^{12}$

$x_{0}=14.755 \pm 0.699 \quad x_{0}=15.298 \pm 0.233$

$\mathrm{d} x=5.342 \pm 0.905 \quad \mathrm{~d} x=5.317 \pm 0.183$

- Fit to determine the instrumental fractionation of the ${ }^{20} \mathrm{Ne} /{ }^{22} \mathrm{Ne}$ ratio for each radial distance on the concentrator $\mathrm{SiC}$ quadrant

- ${ }^{20} \mathrm{Ne}$ fluence fit to determine ${ }^{20} \mathrm{Ne}$ concentration factors for each radial distance on the concentrator $\mathrm{SiC}$ quadrant by dividing the fluence by the bulk solar wind ${ }^{20} \mathrm{Ne}$ fluence $\left(1.19 \times 10^{12}\right.$ atoms $\mathrm{cm}^{-2}$ )

- Fractionation per mass unit is to be applied per mass unit to correct the measured isotopic compositions per mass unit of other elements

- Data and fit are shown in Table 2 and Fig. 5

- Concentration factors are used to determine the bulk solar wind fluences of other elements measured in the concentrator target

- Data and fit are shown in Table 2 and Fig. 4.

Table 5. Preliminary results from the ion-optical simulation of the Genesis concentrator performance.

\begin{tabular}{lcccc}
\hline \multirow{2}{*}{$\begin{array}{l}\text { Radial } \\
\text { distance }\end{array}$} & \multicolumn{5}{l}{ Model concentration factors } \\
\cline { 2 - 4 } & ${ }^{20} \mathrm{Ne}$ & & \multicolumn{3}{l}{$\mathrm{SiC}$} & \\
\hline 2.5 & ${ }^{20} \mathrm{Ne}$ & ${ }^{16} \mathrm{O}$ & ${ }^{14} \mathrm{~N}$ \\
7.5 & 40.5 & 57.8 & 56.2 & 56.9 \\
12.5 & 36.7 & 51.9 & 50.5 & 50.7 \\
17.5 & 27.6 & 38.4 & 37.8 & 37.6 \\
22.5 & 17.2 & 23.5 & 23.5 & 23.2 \\
27.5 & 9.27 & 12.5 & 12.6 & 12.5 \\
30.5 & 4.69 & 6.35 & 6.47 & 6.41 \\
\hline
\end{tabular}

Note: Data were histogrammed in $5 \mathrm{~mm}$ radial bins. The center of the bin is given as the radial distance.

Positions 9, 11, and 12, which are outside the traverse for oxygen and nitrogen (Figs. 2 and 4), were analyzed to test how the gold cross and the assemblage frame may have influenced concentrations and the isotopic composition of the implanted solar wind ions in adjacent areas on the concentrator target quadrants. 


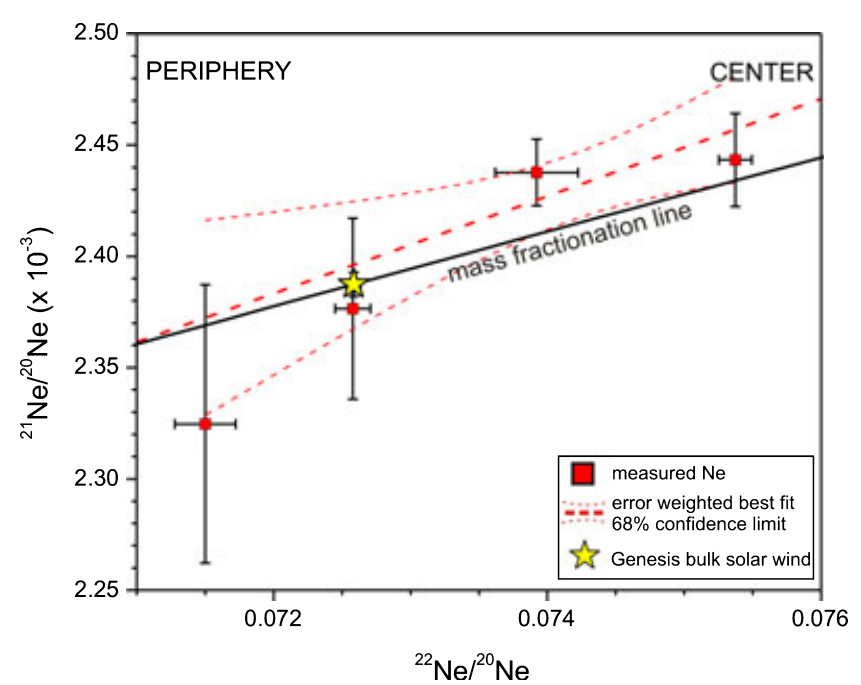

Fig. 6. Mean Ne isotopic compositions (with $1 \sigma$ uncertainties) measured at four positions on the $\mathrm{SiC}$ quadrant with the conventional mass spectrometer are plotted in a Ne threeisotope diagram. An error-weighted best fit (with $1 \sigma$ confidence limits) is given. The mass-dependent fractionation line is drawn through the Genesis bulk solar wind Ne isotopic composition (Heber et al. 2009a). This plot indicates that the concentrator-induced isotopic fractionation is mass-dependent as already suggested by Marty et al. (2010).

The fluence at the outer edge (position 11) seems to have been unaffected by the adjacent outer frame, which is about $0.5 \mathrm{~mm}$ above the quadrants. By contrast, the gold cross, which protrudes approximately $1 \mathrm{~mm}$ above the quadrants, partly shadowed an approximately $1 \mathrm{~mm}$ broad area (positions 9 and 12) adjacent to the totally shadowed area up to $2.7 \mathrm{~mm}$ from the target center. The isotopic composition has not been influenced by the partial shadowing. Nevertheless, future analyses should avoid the $1 \mathrm{~mm}$ broad zone adjacent to all totally shadowed areas surrounding the quadrants. The data from these three positions are not further considered.

\section{Ne Isotopic Compositions}

The $\mathrm{Ne}$ isotopic composition is light at the periphery of the $\mathrm{SiC}$ quadrant $\left({ }^{20} \mathrm{Ne} /{ }^{22} \mathrm{Ne}: 14.07\right)$ relative to bulk solar wind $\left({ }^{20} \mathrm{Ne} /{ }^{22} \mathrm{Ne}\right.$ : 13.78) (Fig. 5) (Heber et al. 2009a) and monotonically evolves toward heavier composition toward the center $\left({ }^{20} \mathrm{Ne} /{ }^{22} \mathrm{Ne}\right.$ : 13.21). The relative difference over the sampled radial distance is $3.17 \%$ per mass unit. All data plot within uncertainties on the error-weighted sigmoidal fit for the entire length of the radius of the $\mathrm{SiC}$ quadrant (Fig. 5). The ${ }^{20} \mathrm{Ne} /{ }^{22} \mathrm{Ne}$ ratios obtained by the two different mass spectrometers agree well with each other.

Figure 6 shows the four data points obtained by the conventional mass spectrometer in a $\mathrm{Ne}$ three-isotope
Table 6. SRIM-based backscatter losses of ${ }^{20} \mathrm{Ne}$ in $\mathrm{SiC}, \mathrm{DOS}$, and gold and related isotope fractionation.

\begin{tabular}{|c|c|c|c|}
\hline & $\begin{array}{l}\text { Angle of } \\
\text { incidence }\left({ }^{\circ}\right)\end{array}$ & $\begin{array}{l}\text { Loss of } \\
{ }^{20} \mathrm{Ne}(\%)\end{array}$ & $\begin{array}{l}\text { Factor to correct } \\
{ }^{20} \mathrm{Ne} /{ }^{22} \mathrm{Ne}\end{array}$ \\
\hline \multirow[t]{3}{*}{$\mathrm{Au}$} & 0 & 22.1 & 1.0133 \\
\hline & 45 & 33.5 & 1.0148 \\
\hline & 55 & 40.0 & 1.0155 \\
\hline \multirow[t]{3}{*}{$\mathrm{C}(\mathrm{DOS})$} & 0 & $<0.001$ & 1 \\
\hline & 45 & 0.17 & 1.00053 \\
\hline & 55 & 0.88 & 1.0021 \\
\hline \multirow[t]{3}{*}{$\mathrm{SiC}$} & 0 & 0.13 & 1.00047 \\
\hline & 45 & 1.78 & 1.0027 \\
\hline & 55 & 4.34 & 1.0040 \\
\hline
\end{tabular}

diagram. The data points fall within their $2 \sigma$ uncertainties on the mass-dependent fractionation line drawn through the bulk solar wind $\mathrm{Ne}$ isotopic composition $\quad\left({ }^{20} \mathrm{Ne} /{ }^{22} \mathrm{Ne}: \quad 13.78 \pm 0.01, \quad{ }^{21} \mathrm{Ne} /{ }^{22} \mathrm{Ne}\right.$ : $0.0329 \pm 0.0001$; Heber et al. 2009a). This demonstrates that the isotopic fractionation caused by the concentrator is mass-dependent, which is an expected consequence of the ion-optical design of the concentrator and as previously suggested by Marty et al. (2010) on the basis of $\mathrm{Ne}$ isotopic measurements in the gold cross.

To effect the best corrections for concentratorinduced fractionations, especially oxygen and nitrogen, it is important to obtain the highest accuracy and precision possible for all $\mathrm{Ne}$ isotopic measurements. The high-sensitivity mass spectrometer enabled us to perform multiple analyses at each radial position with long integration times (e.g., $60 \mathrm{~s}$ for ${ }^{22} \mathrm{Ne}$ ). The standard deviation of the mean ${ }^{20} \mathrm{Ne} /{ }^{22} \mathrm{Ne}$ ratios is on average $2.0 \%$ o $(1 \sigma)$ (Table 2$)$ and the average standard error of the mean is $1.2 \%(1 \sigma)$. The $95 \%$ confidence limit of the sigmoidal fit to the ${ }^{20} \mathrm{Ne} /{ }^{22} \mathrm{Ne}$ data corresponds to an uncertainty of $2.5 \pm 0.3 \%$ within a radial range from 5 to $28 \mathrm{~mm}$, the range suitable for analysis.

To compare the isotopic composition of $\mathrm{Ne}$ with those measured for $\mathrm{He}$ and $\mathrm{Ar}$ (see below) as well as with those derived from ion-optical simulation (Heber et al. 2007, 2010b), we calculate the permil deviation of the measured data (sample) from the passively collected bulk solar wind composition ("standard"; Heber et al. 2009a), according to the following equation:

$$
\delta^{22} \mathrm{Ne}(\%)=\left[\frac{R_{\text {sample }}}{R_{\text {standard }}}-1\right] \times 1000,
$$

where $R$ represents the ratio ${ }^{22} \mathrm{Ne} /{ }^{20} \mathrm{Ne}$. As shown in Heber et al. (2007) for the gold cross and in Heber et al. (2010b) for the SiC quadrant the preliminary, 
Table 7. Laboratory implantation experiment: Measured and backscatter-corrected mean Ne isotopic compositions and ${ }^{20} \mathrm{Ne}$ fluences.

\begin{tabular}{|c|c|c|c|c|c|c|}
\hline \multirow[b]{2}{*}{ Material } & \multirow[b]{2}{*}{$\begin{array}{l}\text { Angle of } \\
\text { incidence }\left(^{\circ}\right)\end{array}$} & \multirow[b]{2}{*}{$\begin{array}{l}n \\
\text { analyses }\end{array}$} & \multicolumn{2}{|c|}{${ }^{20} \mathrm{Ne} /{ }^{22} \mathrm{Ne}\left(\%\right.$ deviation to DOS- $\left.0^{\circ}\right)$} & \multicolumn{2}{|c|}{${ }^{20} \mathrm{Ne}\left(\times 10^{13}\right.$ atoms $\left.\mathrm{cm}^{-2}\right)$} \\
\hline & & & Measured & $\begin{array}{l}\text { Backscatter } \\
\text { corrected }\end{array}$ & Measured & $\begin{array}{l}\text { Backscatter } \\
\text { corrected }\end{array}$ \\
\hline$D O S$ & 0 & & $10.392 \pm 0.005$ & & & \\
\hline \multirow[t]{3}{*}{ DOS } & 0 & 7 & $0 \pm 0.05$ & 0 & $11.04(9)$ & 11.04 \\
\hline & 45 & 5 & $-0.09 \pm 0.19$ & -0.04 & $10.88(16)$ & 10.90 \\
\hline & 55 & 4 & $-0.71 \pm 0.10$ & -0.51 & $10.75(11)$ & 10.84 \\
\hline \multirow{3}{*}{$\begin{array}{l}\text { Smooth } \\
\text { gold (AuoS) }\end{array}$} & 0 & 3 & $-1.27 \pm 0.03$ & -0.04 & $8.61(7)$ & 11.05 \\
\hline & 45 & 3 & $-1.30 \pm 0.07$ & 0.16 & $7.54(4)$ & 11.35 \\
\hline & 55 & 3 & $-1.68 \pm 0.28$ & -0.16 & $6.87(6)$ & 11.45 \\
\hline \multirow{3}{*}{$\begin{array}{l}\text { Rough } \\
\text { gold (AuSS) }\end{array}$} & 0 & 5 & $-5.5 \pm 0.4$ & -4.2 & $5.86(21)$ & 7.52 \\
\hline & 45 & 5 & $-4.8 \pm 0.3$ & -3.4 & $5.55(6)$ & 8.34 \\
\hline & 55 & 6 & $-9.8 \pm 2.6$ & -8.4 & $3.7(1.1)$ & 6.08 \\
\hline$D O S$ & 0 & & $10.268 \pm 0.015$ & & & \\
\hline \multirow[t]{3}{*}{ DOS } & 0 & 6 & $0 \pm 0.15$ & 0 & $9.74(3)$ & 9.74 \\
\hline & 45 & 6 & $-0.20 \pm 0.19$ & -0.15 & $9.52(4)$ & 9.54 \\
\hline & 55 & 7 & $-0.48 \pm 0.19$ & -0.27 & $9.55(4)$ & 9.63 \\
\hline \multirow[t]{3}{*}{$\mathrm{SiC}$} & 0 & 9 & $0.12 \pm 0.14$ & 0.17 & $9.64(3)$ & 9.65 \\
\hline & 45 & 8 & $-0.49 \pm 0.18$ & -0.22 & $9.35(2)$ & 9.51 \\
\hline & 55 & 5 & $-1.11 \pm 0.22$ & -0.71 & $8.78(3)$ & 9.16 \\
\hline
\end{tabular}

Notes: Errors of measured data are $1 \sigma$ standard deviation of $n$ analyses. Uncertainties of the ${ }^{20} \mathrm{Ne} /{ }^{22} \mathrm{Ne} \%$ deviations contain only the uncertainty of the sample data and not those from the reference DOS- $0^{\circ}$. The reference DOS- $0^{\circ}$ values are shown in italics. Backscatter correction is based on SRIM (Table 6), no error is given for the corrected values as the accuracy of SRIM is not known. DOS $=$ diamondlike carbon on silicon.

modeled $\delta^{22} \mathrm{Ne}$ curves differ from the measured isotopic compositions. The ion-optical simulations of the isotopic fractionation have to date consistently underestimated the gradient between center and periphery of the target. Isotopic fractionation associated with backscatter loss and/or the rough surface of the gold cross were possible explanations (see the Gold Cross and Laboratory Implantation Experiments sections). The surface of the $\mathrm{SiC}$ quadrant, on the other hand, is smooth. Backscatter loss of ${ }^{20} \mathrm{Ne}$ from $\mathrm{SiC}$ predicted by SRIM is only $4 \%$ at an angle of incidence of $55^{\circ}$ (compared to $40 \%$ in gold!) and the ${ }^{20} \mathrm{Ne} /{ }^{22} \mathrm{Ne}$ fractionation is $4 \%$ (Table 6). Although SRIM somewhat underestimates backscatter loss and fractionation at high angles of incidence (see the Laboratory Implantation Experiments section), the extent of isotopic fractionation due to backscattering is too small $\left(\sim 7 \%\right.$ at $55^{\circ}$; Table 7$)$ to account for the detected difference between modeled and measured data. We are thus confident that the measured $\mathrm{Ne}$ isotopic composition curve reflects the true fractionation. This is shown by our consistent and extensive data set on several sections of the concentrator target ( $\mathrm{SiC}$ quadrant, four gold cross arms) produced over an extended period of time. We exclude analytical artifacts as a cause of the discrepancy between measured and modeled data. Rather, it is likely that an input parameter to the ion-optical simulation is responsible. A re-examination of the solar wind angular distribution as determined by the Genesis ion monitor instrument (Barraclough et al. 2003) is planned, as this strongly affects the fractionation gradient.

\section{$\mathrm{He}, \mathrm{Ne}$, and $\mathrm{Ar}$ in $\mathrm{SiC}$}

Figure 7 shows the measured fluences of ${ }^{4} \mathrm{He},{ }^{20} \mathrm{Ne}$, and ${ }^{36} \mathrm{Ar}$ in the $\mathrm{SiC}$ quadrant (Tables 2 and 3 ) expressed as concentration factors relative to bulk solar wind fluences. These were measured in DOS from the Genesis passive collectors and adjusted for the slightly shorter exposure time of the concentrator (Heber et al. 2009a). The measured concentration factors of ${ }^{4} \mathrm{He}$ and ${ }^{20} \mathrm{Ne}$ are in good agreement with each other. We calculated the total numbers of ${ }^{4} \mathrm{He},{ }^{20} \mathrm{Ne}$, and ${ }^{36} \mathrm{Ar}$ atoms $(N)$ by integrating the fluences $(F)$ over the entire concentrator target area ( $r=$ radius).

$$
N=\int F(r) 2 \pi r \mathrm{~d} r
$$

The resulting overall ${ }^{4} \mathrm{He} /{ }^{20} \mathrm{Ne}$ ratio is 662.4 and is within $1 \%$ of the bulk solar wind ${ }^{4} \mathrm{He} /{ }^{20} \mathrm{Ne}$ ratio (655.7) obtained from the passive collectors (Heber 


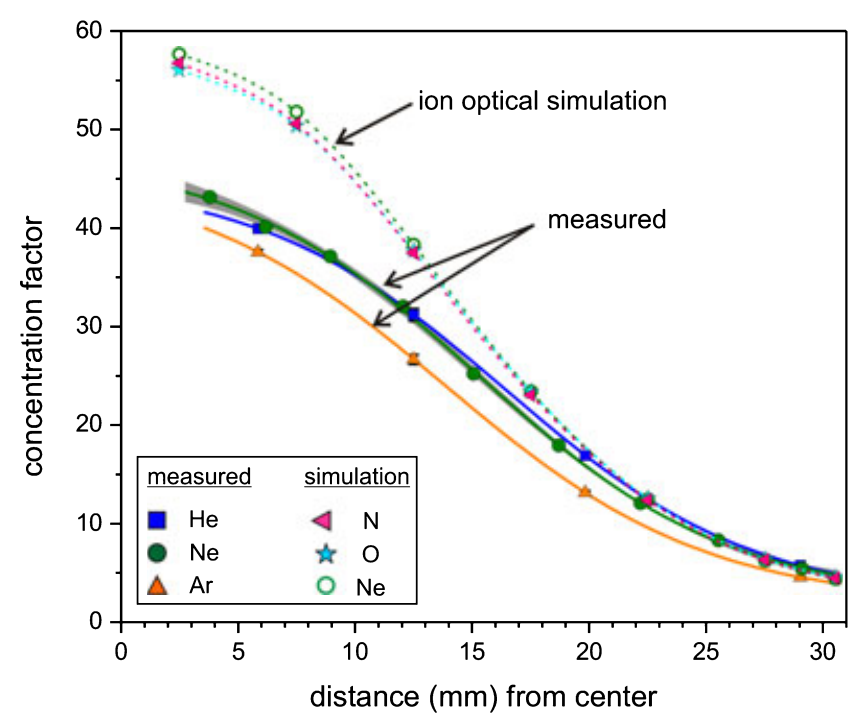

Fig. 7. Concentration factors as function of the concentrator target radius. Measured data $(\mathrm{He}, \mathrm{Ne}$, and $\mathrm{Ar})$ have been fitted by error-weighted sigmoidal functions (solid lines). Concentration factors of $\mathrm{N}, \mathrm{O}$, and $\mathrm{Ne}$ (dotted lines) were obtained independently by ion-optical simulations of the concentrator performance (see the Neon Isotopic Compositions and Fluences Measured in the SiC Quadrant section).

et al. 2009a). For this integrated fluence ratio, $\mathrm{He}$ and $\mathrm{Ne}$ data were taken from the conventional mass spectrometer. It is rather surprising that the overall measured ${ }^{4} \mathrm{He} /{ }^{20} \mathrm{Ne}$ ratio agrees so closely with the bulk solar wind, as backscatter loss of $\mathrm{He}$ from $\mathrm{SiC}$ is expected to be slightly higher than that of $\mathrm{Ne}$.

Integrated fluences of ${ }^{3} \mathrm{He}$ and ${ }^{4} \mathrm{He}$ result in an overall ${ }^{3} \mathrm{He} /{ }^{4} \mathrm{He}$ ratio in the concentrator target of $4.61 \times 10^{-4}$, which is within $0.7 \%$ of the bulk solar wind composition $\left(4.64 \times 10^{-4}\right)$. These data indicate that rejection of both ${ }^{3} \mathrm{He}$ and ${ }^{4} \mathrm{He}$ by the concentrator hydrogen rejection grid can be largely excluded even though solar wind ${ }^{3} \mathrm{He}$ with a $m / q$ of 1.5 is outside the $m / q$ range of 2-4.3 for which the concentrator was nominally designed. By contrast, the overall ${ }^{36} \mathrm{Ar} /{ }^{20} \mathrm{Ne}$ and ${ }^{38} \mathrm{Ar} /{ }^{20} \mathrm{Ne}$ ratios in the concentrator target are, respectively, 16 and $22 \%$ lower than the bulk solar wind values measured in DOS. This indicates that a fraction of the Ar ions, those with lower charge states (leading to $m / q \gg 4.3$ ) or those traveling at higher speed, were lost because they hit the mirror electrode. Because ${ }^{38} \mathrm{Ar}$ has an even higher $m / q$ ratio than ${ }^{36} \mathrm{Ar}$, we anticipate a greater loss of ${ }^{38} \mathrm{Ar}$ relative to ${ }^{36} \mathrm{Ar}$. In detail, the concentration factor of ${ }^{36} \mathrm{Ar}$ is $9 \%$ lower than that of $\mathrm{Ne}$ in the center of the concentrator target; this difference increases to $21 \%$ at the periphery. Based on our measurements and ion-optical simulation in $\mathrm{SiC}$ we conclude that, with the exception of $\mathrm{Ar}$, the concentration factor profiles are very similar for all

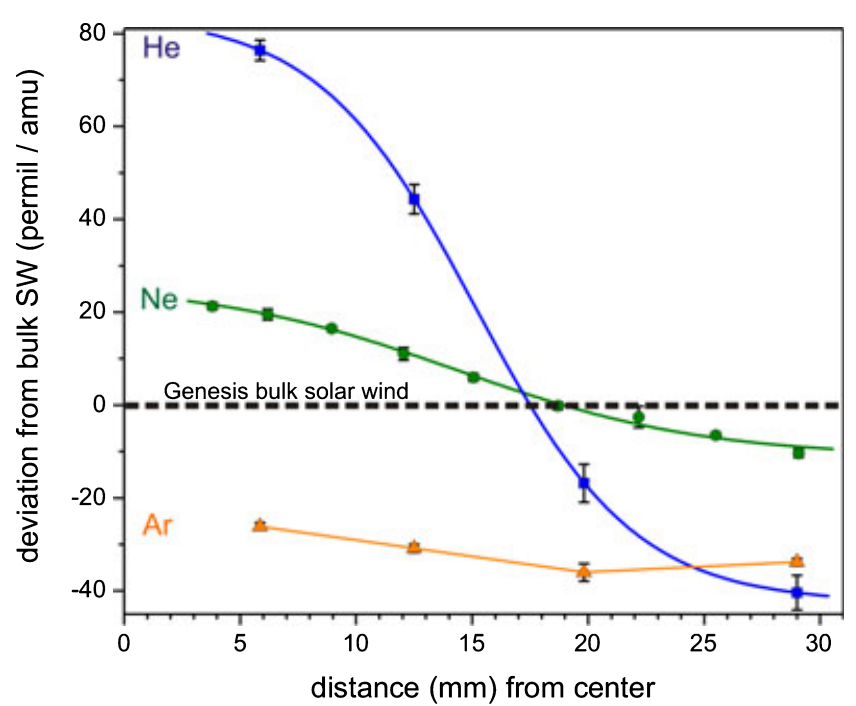

Fig. 8. Isotopic composition of $\mathrm{He}, \mathrm{Ne}$, and $\mathrm{Ar}$ measured in the $\mathrm{SiC}$ quadrant expressed as $\%$ deviation per mass unit relative to bulk solar wind composition (the respective light isotopes being in the denominator). Error bars represent $1 \sigma$ standard deviation of the measured data. The He isotopes were much more strongly fractionated than the $\mathrm{Ne}$ isotopes. However, the cross-over with the true bulk solar wind composition is nearly at the same radius for $\mathrm{Ne}$ and $\mathrm{He}$. By contrast, the Ar isotopic composition is lighter than the bulk solar wind over the entire radius, indicating that ${ }^{38} \mathrm{Ar}$ ions, due to their higher $m / q$ ratios, were preferentially depleted relative to ${ }^{36} \mathrm{Ar}$.

elements, although the measured and model values differ (cf. Fig. 7). The lower concentration factors for Ar are qualitatively understood as the concentrator was not designed to focus the full spectrum of $\mathrm{m} / \mathrm{q}$ and velocity for solar wind Ar.

Figure 8 and Table 3 show the isotopic composition of $\mathrm{He}, \mathrm{Ne}$, and Ar expressed as permil deviation per mass unit relative to bulk solar wind composition (according to Equation 1). The $\mathrm{He}$ isotopic fractionation has a much stronger gradient than that of $\mathrm{Ne}$; the overall difference of the ${ }^{4} \mathrm{He} /{ }^{3} \mathrm{He}$ ratio across the sampled radial positions is $120 \%$. The accepted (i.e., unfractionated) bulk solar wind $\mathrm{He}$ composition is found at nearly the same radial position $(17.5 \mathrm{~mm})$ as the true $\mathrm{Ne}$ composition $(19 \mathrm{~mm})$. The $\mathrm{Ar}$ isotopic composition is lighter than that of the bulk solar wind by $-30 \%$ per mass unit across the entire target radius, illustrating the effects of incomplete concentration of an element in the concentrator.

\section{Gold Cross}

The Ne isotopic data measured in the first two arms of the gold cross published in Heber et al. (2007) were originally intended to correct the oxygen isotopic data for mass fractionation. The uncertainties associated with 

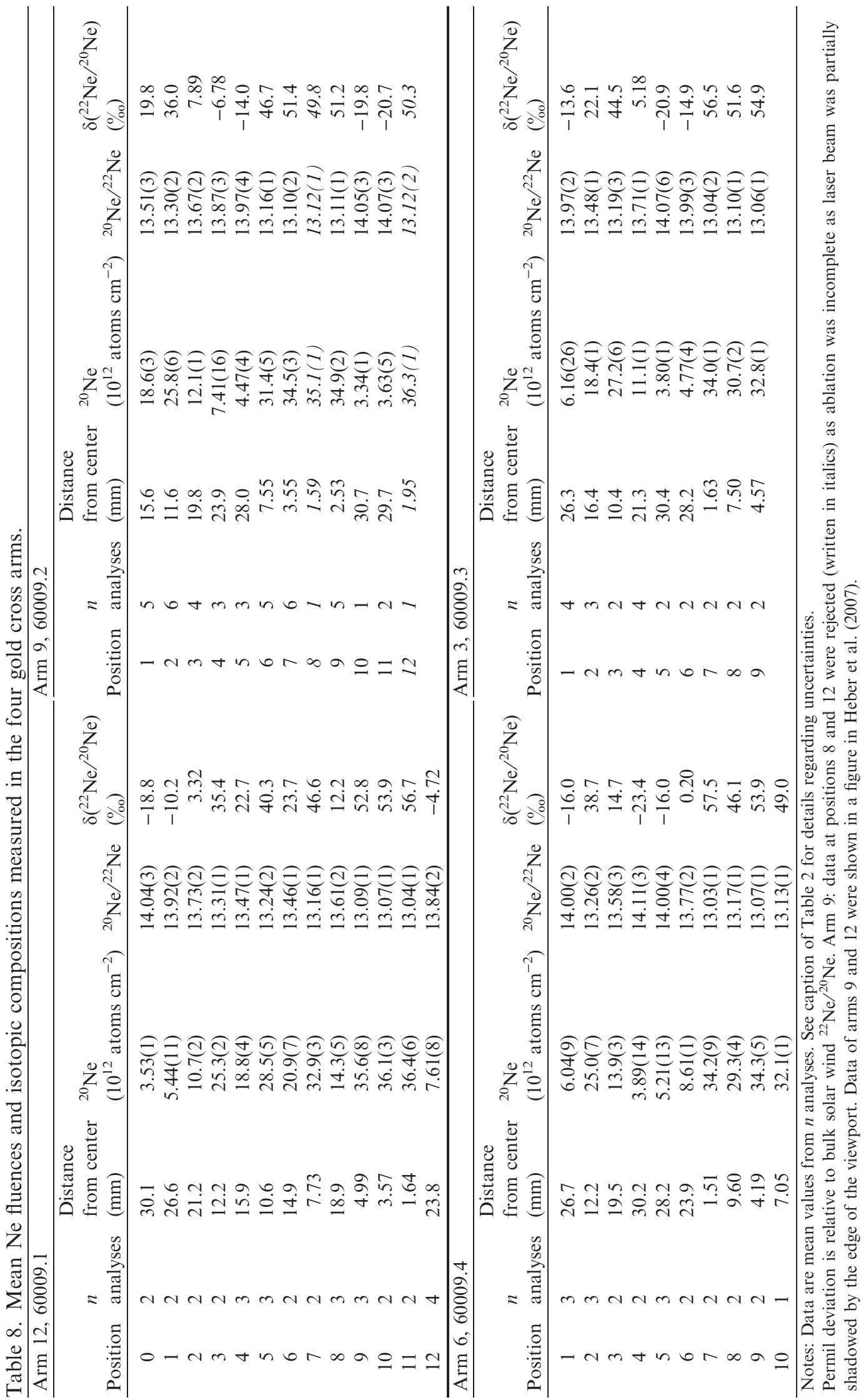


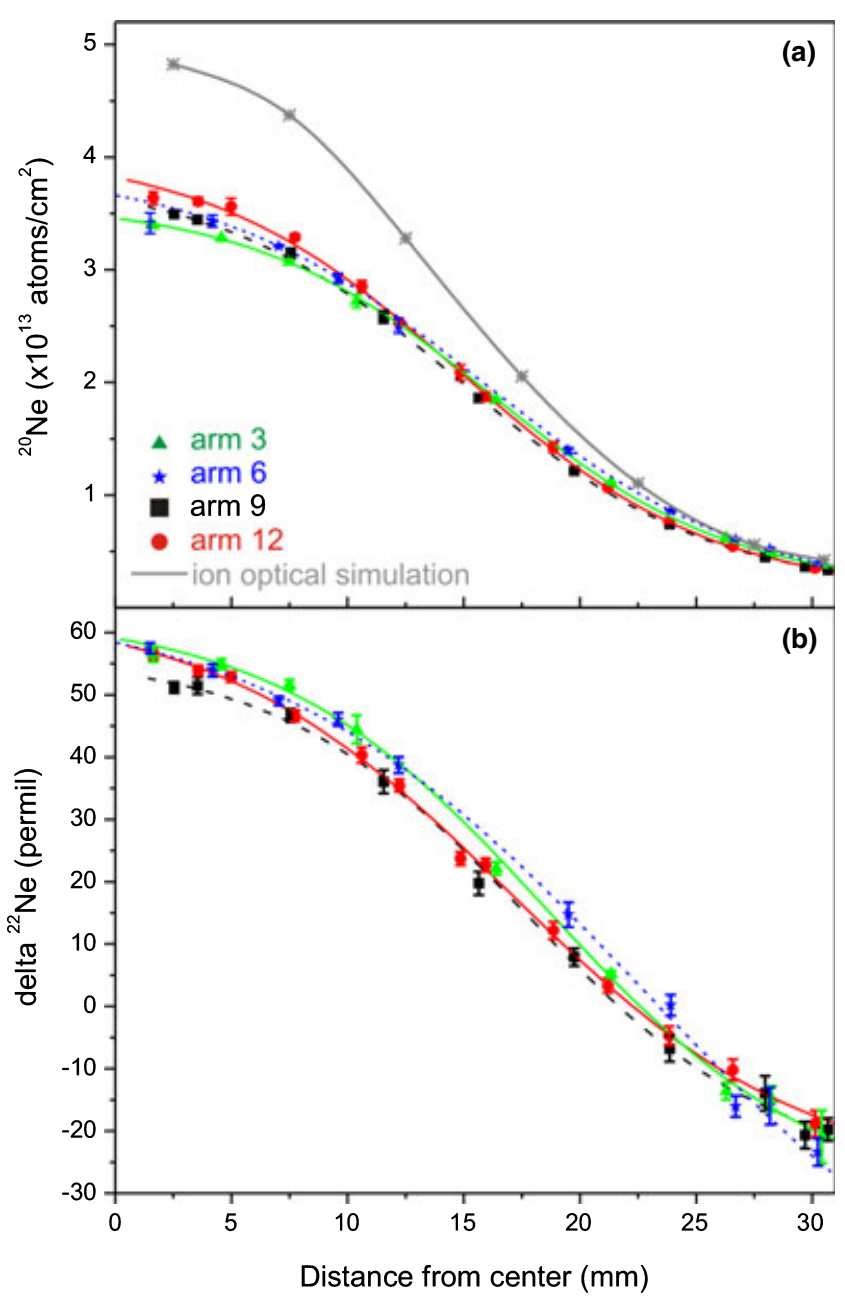

Fig. 9. Mean ${ }^{20} \mathrm{Ne}$ fluences (a) and isotopic compositions $\left(\delta^{22} \mathrm{Ne},[\mathrm{b}] \mathrm{b}\right)$ measured in four gold cross arms and plotted as function of the radial distance from the concentrator target center (error bars are $1 \sigma$ standard deviation). Measured data have been fitted by error-weighted sigmoidal functions. All curves agree within their $95 \%$ confidence limits that are not shown here for clarity. The simulation (published in Heber et al. 2007) represents Ne implantation into Au.

this approach were large and prone to unquantified systematic effects, thus necessitating the analyses of the $\mathrm{SiC}$ quadrant along a radial transect. Nevertheless, the gold cross data permit an important assessment of the azimuthal symmetry of the concentration process; we present the complete data set obtained on all four arms of the cross (Table 8).

Figure 9 shows mean ${ }^{20} \mathrm{Ne}$ fluences and ${ }^{20} \mathrm{Ne} /{ }^{22} \mathrm{Ne}$ ratios of implanted solar wind $\mathrm{Ne}$ as function of the radial position on the four arms of the gold cross. The measured data are not corrected for backscatter loss, so they can be compared directly with the modeled data. The measured fluences and the isotopic abundances agree within their $95 \%$ confidence limits in all four arms along the entire radius. These data indicate that the concentrator focused the ions as designed, and that the ion-optical axis coincided with the target center throughout the mission. Consequently, one radial transect is sufficient to characterize fully the isotopic mass fractionation in the $\mathrm{SiC}$ quadrants.

We now compare the gold cross with the $\mathrm{SiC}$ data, by comparing $\mathrm{Ne}$ fluences and the isotopic compositions in the gold cross arms off their respective sigmoidal fits for the radial distances at which the SiC quadrant was sampled. The ${ }^{20} \mathrm{Ne}$ concentration factor at the periphery of the gold cross is $6.6(r=29.07 \mathrm{~mm})$ relative to the exposure-time corrected ${ }^{20} \mathrm{Ne}$ fluence measured in bulk solar wind gold (AuoS) collector $\left(6.77 \times 10^{11}\right.$ atoms $\mathrm{cm}^{-2}$; Heber et al. 2009a). This factor monotonically increases toward the center to 50.1 at $r=3.80 \mathrm{~mm}$. To reduce the influence of backscatter loss, the concentration factors of the gold cross data were calculated relative to the ${ }^{20} \mathrm{Ne}$ fluence measured on a gold target. The nominal concentration factors in the gold cross are slightly higher than the ones in SiC. This is due to differences in backscatter losses from the rough gold cross and the smooth AuoS, which are not quantifiable (see the Laboratory Implantation Experiments section). We also note that the relative concentration factor from the periphery to the center of the gold cross ( $8.2 \pm 0.7$, averaged for all arms) is in good agreement with the factor from the $\mathrm{SiC}$ quadrant $(7.8 \pm 0.2)$. In absolute numbers, measured ${ }^{20} \mathrm{Ne}$ fluences in the gold cross are on average 33\% lower than the ones in $\mathrm{SiC}$ over the entire radius, in agreement with the amount of backscatter loss from gold compared to $\mathrm{SiC}$ (cf. Fig. 10).

The measured isotopic composition shows a monotonic enrichment of heavy isotopes toward the center of the target. The target-wide (i.e., the ratio of center, $r=3.80 \mathrm{~mm}$, to periphery, $r=29.07 \mathrm{~mm}$ ), measured isotopic fractionation averaged over all arms is $3.60 \pm 0.16 \%$ per mass unit, slightly higher than the relative isotopic fractionation measured across the $\mathrm{SiC}$ quadrant $(3.17 \%$ per mass unit). Only at the periphery do the ${ }^{20} \mathrm{Ne} /{ }^{22} \mathrm{Ne}$ ratios in $\mathrm{SiC}$ and gold cross agree. From the center to $r=20 \mathrm{~mm},{ }^{20} \mathrm{Ne}$ is up to $8 \%$ more depleted relative to ${ }^{22} \mathrm{Ne}$ in the gold cross compared to the $\mathrm{SiC}$. This is presumably due to a preferential loss of ${ }^{20} \mathrm{Ne}$ due to backscattering from the higher mass gold target. The simulated $\mathrm{Ne}$ fluences (Fig. 9) and the $\delta^{22} \mathrm{Ne}$ (Heber et al. 2007) in the gold cross differ from the measured data in a similar fashion as the $\mathrm{SiC}$ data.

In summary, the solar wind particles were focused by the concentrator at the target, and cylindrical symmetry about the concentrator was maintained throughout the mission. 

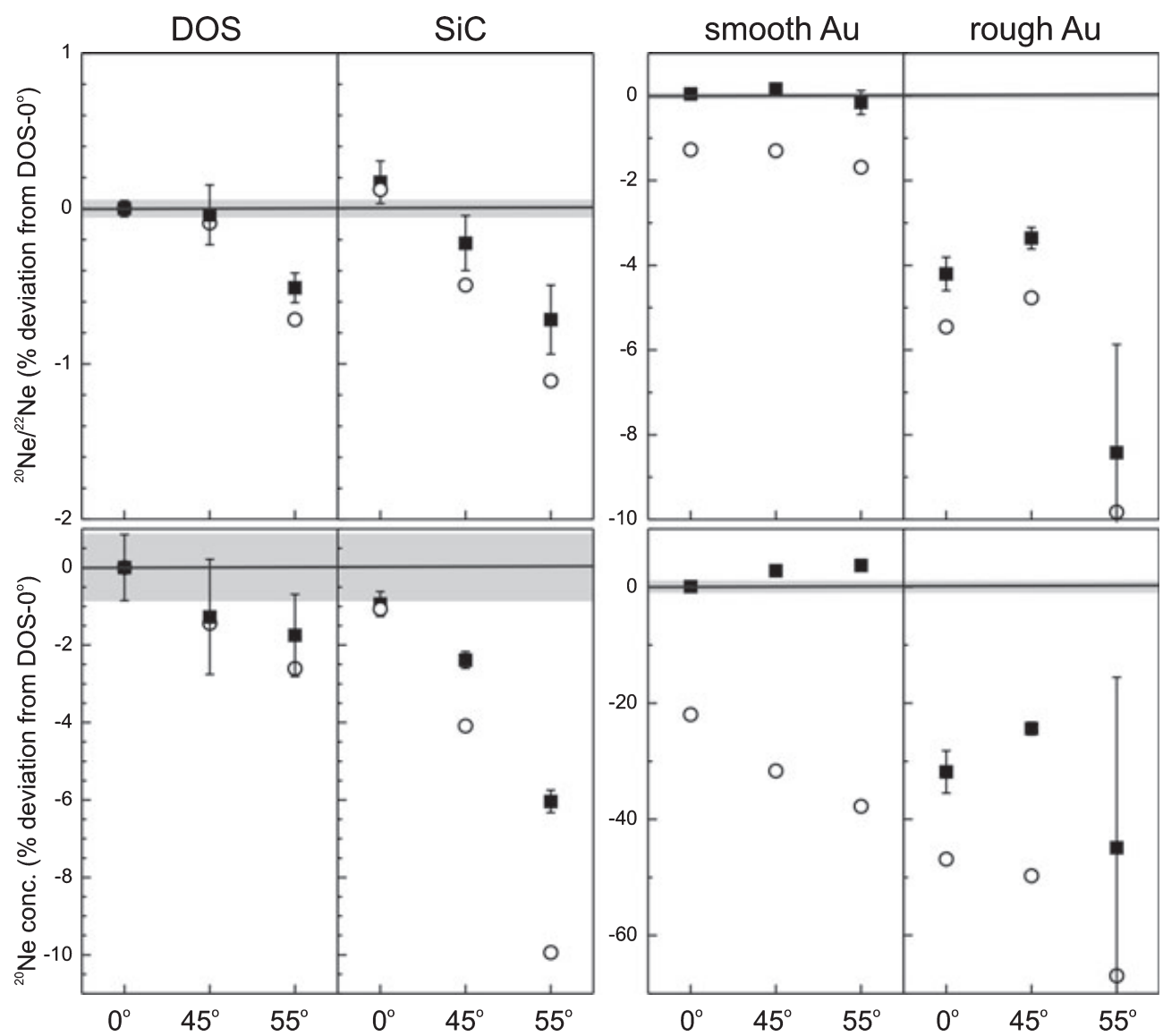

Fig. 10. Laboratory implantation experiment: Ne isotopic composition and ${ }^{20} \mathrm{Ne}$ concentration in DOS, SiC, smooth (AuoS) and rough surface gold (AuSS) shown as percent deviation from respective DOS- $0^{\circ}$ value. Open circles represent the measured data, solid squares the SRIM-based corrected data. Error bars (and the gray bar for the DOS- $0^{\circ}$ reference) correspond to $1 \sigma$ standard deviation. Note the different ordinate scales in the different panels.

\section{Laboratory Implantation Experiments}

Laboratory implantation experiments were carried out to investigate the accuracy of backscatter loss and related isotopic fractionation corrections predicted by SRIM, in particular for irradiation at large angles of incidence. The final objective of these experiments was to better understand the discrepancy between modeled and measured $\mathrm{Ne}$ data in the concentrator gold cross as detected by Heber et al. (2007).

Backscatter loss of ${ }^{20} \mathrm{Ne}$ and ${ }^{22} \mathrm{Ne}$ implanted into DOS at 72 and $74 \mathrm{keV}$ normal to the surface is negligible. This justifies using the DOS- $0^{\circ}$ data as reference points for the other materials and different angles of incidence (Table 7). The Ne data of DOS and DOS-H (irradiated beforehand with $1.8 \times$ $10^{16} \mathrm{H}^{+} \mathrm{cm}^{-2}$ ) were indistinguishable from each other at all three angles of incidence so these measurements were averaged. The $\mathrm{H}$ fluence here is only about $12 \%$ of the solar wind $\mathrm{H}$ fluence received by the concentrator target. Although definite conclusions about radiation damage in the concentrator target are not possible, our data show clearly that a dose of $1.8 \times 10^{16} \mathrm{H}^{+} \mathrm{cm}^{-2}$ does not cause serious radiation damage that would have led to an enhanced diffusive loss. Backscatter loss and isotopic fractionation increase with increasing incidence angles, e.g., DOS- $55^{\circ}$ suffered a $2.6 \%{ }^{20} \mathrm{Ne}$ loss and a $0.7 \%{ }^{20} \mathrm{Ne} /{ }^{22} \mathrm{Ne}$ fractionation. SRIM-derived backscatter corrections for Ne implantation into DOS agree perfectly with measured values for angles up to $45^{\circ}$. However, SRIM values are too small to account for the measured isotopic fractionation at $55^{\circ}$ incidence; the corrected ${ }^{20} \mathrm{Ne} /{ }^{22} \mathrm{Ne}$ ratio is still $0.5 \%$ lower than the reference (Fig. 10). Similar results were obtained for $\mathrm{Ne}$ implantation into SiC. The measured (and corrected) ${ }^{20} \mathrm{Ne}$ loss and the ${ }^{20} \mathrm{Ne} /{ }^{22} \mathrm{Ne}$ fractionation are $10 \%$ $(6 \%)$ and $1.1 \%(0.7 \%)$, respectively, for $\mathrm{SiC}-55^{\circ}$. Thus, it seems that at large angles of incidence $\left(\geq 55^{\circ}\right)$ SRIM underestimates actual backscatter losses of $\mathrm{Ne}$ implanted into a target with a similar mass. This has not been considered so far in the concentrator model calculations. 
${ }^{20} \mathrm{Ne}$ backscatter losses from smooth gold increased from $22 \%$ at $0^{\circ}$ to $37 \%$ at $55^{\circ}$ incidence, and the ${ }^{20} \mathrm{Ne} /{ }^{22} \mathrm{Ne}$ fractionation from 1.3 to $1.7 \%$. SRIMmodeled backscatter losses are in good agreement with the measured data, apart from a slight overcorrection of abundances at larger angles. In stark contrast, the rough gold-representing the gold cross material-is characterized by much larger backscatter losses (50$70 \%$ for $0^{\circ}-55^{\circ}$ ) and ${ }^{20} \mathrm{Ne} /{ }^{22} \mathrm{Ne}$ fractionation $(5-10 \%)$. Because SRIM does not consider surface roughness, the SRIM-based backscatter corrections largely underestimate losses and isotopic fractionation factors caused by backscattering from a rough gold surface. This inhibited the use of the $\mathrm{Ne}$ data from the gold cross to correct the concentrator-induced instrumental fractionation for elements measured in concentrator target quadrants composed of elements significantly lighter in mass than gold. This corroborates the conclusion that instrumental fractionation caused by the concentrator is best reflected by the measured noble gas data in the SiC quadrant.

\section{DISCUSSION}

The isotopic compositions of oxygen and nitrogen recently measured in the $\mathrm{SiC}$ quadrant of the concentrator target (Kallio et al. 2010; McKeegan et al. 2010) must be corrected for mass-dependent fractionation at each radial position on the target to obtain the actual solar wind isotopic composition of these elements. The major purpose of the present work was to provide a reliable basis for such a correction by using precise and accurate measurements of fluences and isotopic compositions of $\mathrm{Ne}$ as a function of the radial position on the concentrator target. $\mathrm{Ne}$ is abundant in the solar wind, relatively easy to measure, not affected by terrestrial contamination, and has a similar mass-to-charge ratio, $\mathrm{m} / \mathrm{q}$, in the solar wind as oxygen. A second purpose of this work was to evaluate the possibility of using the measured $\mathrm{Ne}$ fluences in the target in conjunction with the known Ne fluence in the bulk solar wind to determine concentration factors which then can be used to obtain bulk solar wind fluences of other elements via measurements in the concentrator target.

\section{Correcting the Isotopic Composition for Instrumental Mass Fractionation}

Here, we discuss how the measured ${ }^{20} \mathrm{Ne} /{ }^{22} \mathrm{Ne}$ provides a sound basis for the correction of the concentrator instrumental mass fractionation. These corrections must be based on the ${ }^{20} \mathrm{Ne} /{ }^{22} \mathrm{Ne}$ curve measured in the $\mathrm{SiC}$ quadrant in relation to the
${ }^{20} \mathrm{Ne} /{ }^{22} \mathrm{Ne}$ composition of the bulk solar wind derived from the passive collectors of the $\mathrm{B} / \mathrm{C}$ arrays on the Genesis spacecraft (Heber et al. 2009a). There are three essential questions that need to be addressed to justify this approach:

1. Can the bulk solar wind ${ }^{20} \mathrm{Ne} /{ }^{22} \mathrm{Ne}$ ratio obtained from the $\mathrm{B} / \mathrm{C}$ passive collectors be used as reference, i.e., can we be sure that both the concentrator and the $\mathrm{B} / \mathrm{C}$ arrays were exposed to solar wind of identical composition?

2. Can the ${ }^{20} \mathrm{Ne} /{ }^{22} \mathrm{Ne}$-based isotopic fractionation factor directly be applied to correct other elements, e.g., the ${ }^{16} \mathrm{O} /{ }^{18} \mathrm{O}$ ratio, without requiring any additional correction due to a potentially different ion-optical behavior of the neon isotopes relative to those of oxygen (or nitrogen)?

3. Do we have to consider backscattering as an additional factor that could result in different extents of isotopic fractionation of oxygen, nitrogen, and neon?

\section{Bulk Solar Wind ${ }^{20} \mathrm{Ne}^{22} \mathrm{Ne}$ from the Passive Genesis Collector as Reference?}

Although there are small differences in collection times we believe both collectors, the passive collector and the concentrator, obtained essentially identical samples of the solar wind. The Genesis B/C arrays collected solar wind for 852.83 days. The concentrator was in operation for 803.28 of these days. For about 39 of the missing 50 days, the concentrator was in standby mode for maintenance work. These interruptions were independent from prevailing solar wind conditions. Only 11 of the missing days occurred because of solar wind conditions unfavorable for concentrator operation: for in total 3.3 days the solar wind speed exceeded $800 \mathrm{~km} \mathrm{~s}^{-1}$ during the main collection period of 2002 2004 and for 7.6 days the solar wind speed exceeded $600 \mathrm{~km} \mathrm{~s}^{-1}$ during the final 37 days of collection in 2004. Periods of solar wind $>800 \mathrm{~km} \mathrm{~s}^{-1}$ contributed $1 \%$ to the total $\mathrm{He}$ fluence, as measured with the Genesis ion monitor, and the 7.6 days in standby mode near the end of the collection period contributed merely about $0.15 \%$ of the total He. Moreover, the ${ }^{20} \mathrm{Ne} /{ }^{22} \mathrm{Ne}$ ratio in the fast $\left(>500 \mathrm{~km} \mathrm{~s}^{-1}\right)$ solar wind regime collected by Genesis differs by only $0.5 \%$ from the bulk solar wind value (Heber et al. 2009b). The impact of the missing fractions of high-speed solar wind on the bulk solar wind elemental and isotopic composition collected by the concentrator is minor $(\ll 0.1 \%)$, justifying the use of the passively collected bulk solar wind ${ }^{20} \mathrm{Ne} /{ }^{22} \mathrm{Ne}$ ratio as a reference. We can likewise assume that oxygen and nitrogen sampled by the concentrator target is representative of bulk solar wind oxygen and nitrogen. 


\section{Applicability of the ${ }^{20} \mathrm{Ne} /{ }^{22} \mathrm{Ne}$-Based Fractionation Factor to Oxygen and Nitrogen Isotope Measurements}

Helium isotopes were more strongly fractionated than $\mathrm{Ne}$ in the concentrator (Fig. 8), suggesting that it may not be straightforward to correct oxygen and nitrogen based on Ne data. Because the concentrator is an electrostatic device, elements were fractionated according to their mass-to-charge ratio $(\mathrm{m} / \mathrm{q})$. The major charge states of $\mathrm{Ne}, \mathrm{O}$, and $\mathrm{N}$ are $+8,+6$, and +5 , respectively (see, e.g., von Steiger et al. 2000; Gloeckler and Geiss 2007), resulting in $\mathrm{m} / q$ values of $2.5\left({ }^{20} \mathrm{Ne}\right), 2.7\left({ }^{16} \mathrm{O}\right)$, and $2.8\left({ }^{14} \mathrm{~N}\right)$. The $\mathrm{m} / q$ of ${ }^{4} \mathrm{He}$, which all have a charge state of +2 , differs significantly $(m / q=2)$ from neon, oxygen, and nitrogen. The degree of isotopic fractionation is governed by the mass ratio of its different isotopes (as $q$ is the same for all isotopes of the same element). The $m_{3 \mathrm{He}} / m_{4 \mathrm{He}}$ ratio of 0.75 far from unity qualitatively explains the large observed fractionation. Mass ratios of ${ }^{20} \mathrm{Ne} /{ }^{22} \mathrm{Ne}(0.91)$ and ${ }^{16} \mathrm{O} /{ }^{18} \mathrm{O}(0.89)$, as well as ${ }^{21} \mathrm{Ne} /{ }^{22} \mathrm{Ne}(0.95),{ }^{16} \mathrm{O} /{ }^{17} \mathrm{O}(0.94)$, and ${ }^{14} \mathrm{~N} /{ }^{15} \mathrm{~N}(0.93)$ are very similar to each other, suggesting that the isotopic fractionation per mass unit of ${ }^{16} \mathrm{O} /{ }^{18} \mathrm{O}$, ${ }^{16} \mathrm{O} /{ }^{17} \mathrm{O}$, and ${ }^{14} \mathrm{~N} /{ }^{15} \mathrm{~N}$ induced by the mass-dependent ion trajectories in the concentrator will mimic the fractionation per mass unit of ${ }^{20} \mathrm{Ne} /{ }^{22} \mathrm{Ne}$.

Corroborating evidence is provided by the oxygen isotopic composition measured along the same traverse as the Ne data (McKeegan et al. 2010). The enrichment of the heavy isotope relative to the light one is, within uncertainties, identical for oxygen and neon: on average $28.6 \%$ for ${ }^{18} \mathrm{O}$ (relative to ${ }^{16} \mathrm{O}$ ) and $29.8 \%$ o for ${ }^{22} \mathrm{Ne}$ (relative to ${ }^{20} \mathrm{Ne}$ ) at the radial distance of $5.7 \mathrm{~mm}$ relative to $15.7 \mathrm{~mm}$. While the mass fractionation correction needs to be very precise for oxygen isotopes, the requirements for this correction for nitrogen are less demanding. The measured $\delta^{15} \mathrm{~N}$ in $\mathrm{SiC}$ (Kallio et al. 2010) and in the gold cross (Marty et al. 2010) revealed a solar wind composition of around $-400 \%$, with uncertainties of $\geq 100 \%$. The preliminary modeled isotopic fractionations of $\mathrm{Ne}$ and oxygen in $\mathrm{SiC}$, although different in absolute terms from the measured value (e.g., Heber et al. 2010b), support our conclusion in relative terms.

\section{Backscattering as an Additional Factor Influencing the Extent of Isotopic Fractionation?}

We performed SRIM simulations for ${ }^{14,15} \mathrm{~N}$, ${ }^{20,22} \mathrm{Ne}$, and ${ }^{16,18} \mathrm{O}$ implanted at typical concentrator energies (Fig. 11) into $\mathrm{SiC}$ at different angles of incidence $\left(0^{\circ}-60^{\circ}\right)$. Due to the additional kinetic energy of the solar wind ions provided by the concentrator acceleration voltage and the relatively light mass of $\mathrm{SiC}$, the absolute backscatter losses of nitrogen, oxygen, and

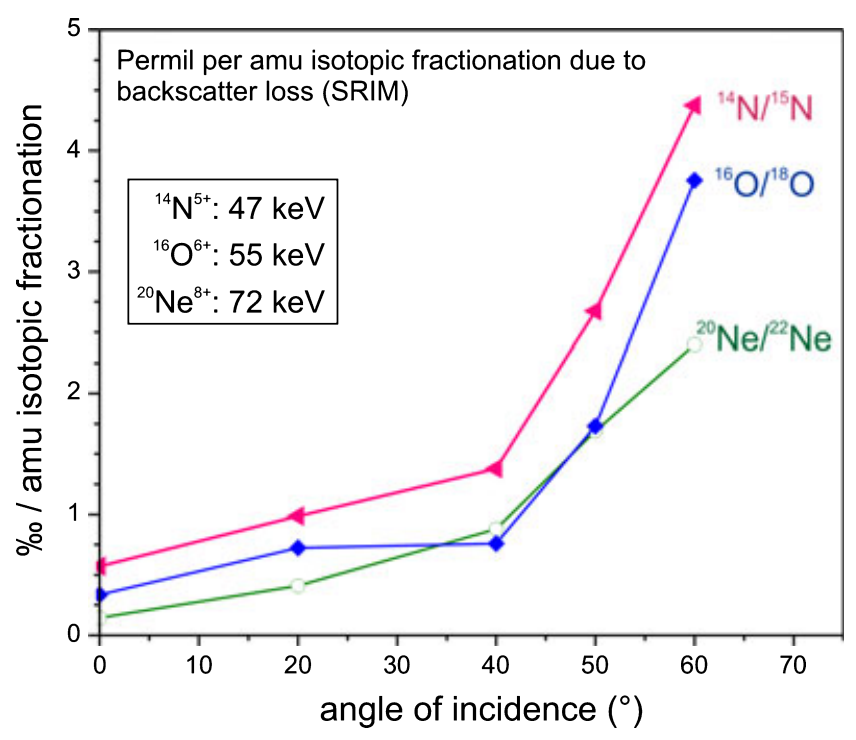

Fig. 11. Backscatter-caused isotopic fractionation in $\mathrm{SiC}$ simulated with SRIM. Indicated ion energies correspond to an assumed initial solar wind energy of $1 \mathrm{keV}$ per mass unit $\left(=440 \mathrm{~km} \mathrm{~s}^{-1}\right)$ plus the postacceleration energy $(6.5 \mathrm{kV} \times$ indicated main charge state of the ion). Fractionation is plotted as function of the angle of incidence. For each case, $1 \times 10^{5}$ ions were simulated. Statistical uncertainties calculated from repeated simulations are in the order of $10 \%$ for low angles (small number of backscattered ions) and $1 \%$ for $60^{\circ}$. The major angles of incidence of ions implanted into the concentrator target were between $40^{\circ}$ and $60^{\circ}$.

neon are quite low even at the large angles of incidence on the concentrator target (about $1 \%$ at $40^{\circ}$ and $8 \%$ at $60^{\circ}$ for the mentioned elements). Backscatter losses are slightly different for different isotopes of an element, leading to a small isotopic fractionation of the retained fraction. For nitrogen, oxygen, and neon expected absolute isotopic fractionations according to SRIM are $\leq 1 \%$ o per mass unit for angles $<40^{\circ}$; and $4.4 \%, 3.8 \%$, and $2.4 \%$ per mass unit at $60^{\circ}$, respectively. The laboratory implantation experiments performed in this work (see the Laboratory Implantation Experiments section, Fig. 10) revealed that SRIM underestimates the actual isotope fractionation for large angles of incidence. We can assume, however, that this difference between predicted and actual backscatter-induced fractionation is similar for all elements within a similar mass range. The SRIM-based relative difference between ${ }^{16} \mathrm{O} /{ }^{18} \mathrm{O}$ and ${ }^{20} \mathrm{Ne} /{ }^{22} \mathrm{Ne}$ fractionation is $0.3 \%$ o per mass unit for angles $\leq 50^{\circ}$ and approximately $1.4 \%$ per mass unit for $60^{\circ}$. The relative difference between ${ }^{14} \mathrm{~N} /{ }^{15} \mathrm{~N}$ and ${ }^{20} \mathrm{Ne} /{ }^{22} \mathrm{Ne}$ fractionation is $<1 \%$ per mass unit for angles $\leq 50^{\circ}$ and $2 \%$ per mass unit for $60^{\circ}$. The major angles of incidence were $40^{\circ}-60^{\circ}$, but the $55^{\circ}-60^{\circ}$ angles predominate only in the outer area of the concentrator target at a radius $>22 \mathrm{~mm}$. Even 
considering that the backscatter-induced isotopic fractionations are somewhat higher for slow solar wind and solar wind in lower charge states than simulated here, we can safely conclude that backscatter-induced differences in the isotopic fractionation of nitrogen, oxygen, and neon in the concentrator target are negligible for the purposes of this study.

\section{Summary for Oxygen and Nitrogen Correction Based on Ne Isotopic Composition}

Based on our observations, we conclude that the most robust indicator of the isotopic mass fractionation is given by the ${ }^{20} \mathrm{Ne} /{ }^{22} \mathrm{Ne}$ measured in the $\mathrm{SiC}$ quadrant of the concentrator target. Accordingly, the measured oxygen and nitrogen isotopic ratios should be corrected based on the radial distance of the respective analysis on the concentrator target using Table 4 . The resulting permil fractionation factors, divided by the mass difference of ${ }^{22} \mathrm{Ne}$ and ${ }^{20} \mathrm{Ne}$ to obtain the fractionation factor per mass unit can be directly subtracted (in per mass unit) from the measured oxygen and nitrogen isotopic compositions. The uncertainty of this correction is $1.25 \%$ o per mass unit as indicated by the $95 \%$ confidence limits of the ${ }^{20} \mathrm{Ne} /{ }^{22} \mathrm{Ne}$ data fit within the radial distance between 5 and $28 \mathrm{~mm}$. It is conceivable that with future analyses of the isotopic compositions of other elements in the concentrator target the fractionation correction based on $\mathrm{Ne}$ can be refined further.

\section{Application to Other Elements}

Helium and Ar data provide insight into the isotopic fractionation of elements lighter than nitrogen and heavier than Ne. The constraints provided by these data are restricted since the He isotopic fractionation is particularly large compared with that of $\mathrm{Ne}$ (Fig. 8) and because Ar was partly lost at the mirror electrode due to its high $m / q$ ratio. Nevertheless, it seems probable that to first order the measured ${ }^{20} \mathrm{Ne} /{ }^{22} \mathrm{Ne}$ fractionation factors per mass unit can be applied to correct ${ }^{12} \mathrm{C} /{ }^{13} \mathrm{C}$ and ${ }^{24} \mathrm{Mg} /{ }^{26} \mathrm{Mg}$ based on their similar mass ratios of 0.92. The $m / q$ of ${ }^{12} \mathrm{C}$ (2.4) and of ${ }^{24} \mathrm{Mg}$ (2.6), based on their major charge states (von Steiger et al. 2000; Gloeckler and Geiss 2007), are close to the value for ${ }^{20} \mathrm{Ne}(2.5)$. The instrumental isotopic fractionations of lithium and boron are more difficult to predict but may be expected to be in-between those of $\mathrm{He}$ and $\mathrm{Ne}$ (Fig. 8).

The situation for elements heavier than about silicon is more problematic. The concentrator can act as a filter against high $\mathrm{m} / \mathrm{q}$ ions so the isotopic fractionation effects may be considerably different from those of Ne. Our Ar measurements reveal an overall ${ }^{36} \mathrm{Ar}$ deficit of $16 \%$ relative to ${ }^{20} \mathrm{Ne}$. The measured $\mathrm{Ar}$ isotopic composition is on average approximately $30 \%$ per mass unit lighter than the bulk solar wind over the entire radius of the target. Lower charge state ions of heavier elements have a high probability of hitting the electrostatic mirror and being lost. These ions have $\mathrm{m} / \mathrm{q}$ ratios that are higher than the operational $\mathrm{m} / q$ range of the concentrator (2-4.3). Based on solar coronal models, the charge states of $\mathrm{Ar}$ in the bulk solar wind range between +7 and +11 , and ${ }^{36} \mathrm{Ar}^{+7}(m / q=5.1)$ and ${ }^{36} \mathrm{Ar}^{+8}(m / q=4.5)$ together account for approximately $20 \%$ of the total solar wind ${ }^{36} \mathrm{Ar}$ fluences (Bochsler, personal communication), close to the observed Ar loss in the concentrator target. In general, for a more quantitative estimate of isotopic fractionation effects of elements heavier than $\mathrm{Si}$ it is important to know the correct charge state distribution of the element. Additional modeling is required to determine the limits of which elements can be concentrated without the type of losses experienced by Ar.

\section{${ }^{20}$ Ne Fluences to Calibrate Solar Wind Elemental Abundances Measured in the Concentrator Target}

We examine here the possibility of using the measured ${ }^{20} \mathrm{Ne}$ fluences to deduce bulk solar wind fluences of other elements measured in the concentrator target. This application of the concentrator was not originally envisaged, but is promising for volatile elements prone to terrestrial contamination (e.g., O, N, C). Solar wind ions are implanted into the concentrator target to a considerably larger depth $(\leq 200 \mathrm{~nm})$ than in the passive collectors $(\leq 60 \mathrm{~nm})$. Thus, almost complete solar wind implantation profiles can be measured in concentrator target quadrants by techniques employing high-depth-resolution secondary ion mass spectrometry (SIMS) despite the presence of surface contamination (e.g., Kallio et al. 2010; McKeegan et al. 2010). By contrast, solar wind is too shallowly implanted in passive collectors to sufficiently resolve surface contamination from the solar wind implantation peak for the mentioned elements even by the most careful SIMS analysis (Heber et al. 2010a).

As shown in the $\mathrm{He}, \mathrm{Ne}$, and $\mathrm{Ar}$ in $\mathrm{SiC}$ section, the total ${ }^{4} \mathrm{He} /{ }^{20} \mathrm{Ne}$ ratio in the concentrator target agrees within $1 \%$ with the value determined for the bulk solar wind. This agreement is better than expected given that the backscatter loss of $\mathrm{He}$ is larger than that of $\mathrm{Ne}$ $\left(4.1 \%\right.$ at $50^{\circ}$ implantation into SiC, SRIM). We exclude significant ${ }^{20} \mathrm{Ne}$ losses due to the high $m / q$ of $\mathrm{Ne}$ as even the very rare, low charge state of $\mathrm{Ne}^{+6}$ results in a $m / q$ of 3.3, well within concentrator operation specifications. The trajectories of the incoming He ions $(m / q=2)$ are more strongly affected by the acceleration grid resulting in a more narrow angular distribution and better 
focusing onto the target. On the other hand, the overall angular distribution of the $\mathrm{Ne}$ ions $(m / q=2.5-3.3)$, after passing the acceleration grid, is more diffuse. It appears that fewer $\mathrm{He}$ ions are lost beyond the edge of the target compared to $\mathrm{Ne}$ ions, which compensates for the increased backscatter loss of He.

In general, as significant contributions to the total $\mathrm{He}$ and $\mathrm{Ne}$ fluences by ions with $\mathrm{m} / q$ larger than 4.3 can be ruled out, we can also assume that all elements between $\mathrm{He}$ and $\mathrm{Ne}$ are approximately equally concentrated as Ne. Analytical techniques (e.g., SIMS, laser ablation) sample only certain areas of the concentrator target. Thus, the solar wind fluence of an element must be inferred based on the radial position of the analyzed area on the target. Therefore, we do not consider the total concentration of $\mathrm{Ne}$ to be relevant in this context, but rather the $\mathrm{Ne}$ concentration factor as a function of the radial distance from the target center. This is calculated from the ${ }^{20} \mathrm{Ne}$ fluence measured in the $\mathrm{SiC}$ quadrant (Fig. 4; Table 4) relative to the ${ }^{20} \mathrm{Ne}$ fluence of the bulk solar wind (Heber et al. 2009a). The measured $\mathrm{He}$ and $\mathrm{Ne}$ concentration factors are in excellent agreement over the entire radial distance of the concentrator target (Fig. 7), differing only between $0.2 \%$ and at maximum $4.4 \%$. Also, the preliminary modeled concentration factors for nitrogen, oxygen, and neon all agree very well with each other over the entire radius, oxygen and nitrogen differing from $\mathrm{Ne}$ at maximum by 3 and $6 \%$, respectively (Fig. 7). This congruency suggests that the $\mathrm{Ne}$ data can be used to deduce solar wind fluences for elements between $\mathrm{He}$ and $\mathrm{Ne}$, and possibly up to $\mathrm{Si}$ by concentrator target measurements with an accuracy in the range of a few percent (and somewhat higher in a relative sense between elements with a similar $m / q$ ).

\section{CONCLUSIONS}

The Genesis concentrator provided enhanced solar wind fluences for the analysis of the isotopic composition of solar wind oxygen and nitrogen. The concentration process caused isotopic fractionation of the implanted solar wind. This work comprehensively characterized this fractionation as well as the concentration factors by analysis of noble gas isotopic and elemental abundances. The major achievements of this work are precisely and accurately measured, high spatial resolution profiles of the ${ }^{20} \mathrm{Ne} /{ }^{22} \mathrm{Ne}$ ratios and the $\mathrm{Ne}$ concentration as functions of the radial position on the same SiC quadrant that was used for oxygen and nitrogen isotopic composition measurements. These ${ }^{20} \mathrm{Ne} /{ }^{22} \mathrm{Ne}$ ratios normalized to the bulk solar wind ${ }^{20} \mathrm{Ne} /{ }^{22} \mathrm{Ne}$ ratio measured on passive Genesis collectors provide the absolute $\mathrm{Ne}$ isotopic fractionation in the
$\mathrm{SiC}$ quadrant and its variation with radial position. The $\mathrm{Ne}$ analyses were complemented by $\mathrm{He}$ and $\mathrm{Ar}$ measurements with lower spatial resolution. Neon threeisotope analyses indicate that the isotopic fractionation is mass-dependent. The bulk solar wind collected by passive Genesis collectors is representative of the bulk solar wind implanted into the concentrator target. Because of the similar mass ratios of the isotopes of nitrogen, oxygen, and neon the isotopic fractionation per mass unit of ${ }^{16} \mathrm{O} /{ }^{18} \mathrm{O},{ }^{16} \mathrm{O} /{ }^{17} \mathrm{O}$, and ${ }^{14} \mathrm{~N} /{ }^{15} \mathrm{~N}$ induced by the mass-dependent ion trajectories in the concentrator is very similar to that of ${ }^{20} \mathrm{Ne} /{ }^{22} \mathrm{Ne}$. Backscatter-induced differences in the isotopic fractionation of nitrogen, oxygen, and neon in the concentrator target can be excluded within uncertainties of the measurements. We adopted the absolute isotopic fractionation of the ${ }^{20} \mathrm{Ne} /{ }^{22} \mathrm{Ne}$ ratio per mass unit measured in the $\mathrm{SiC}$ quadrant to correct the measured oxygen and nitrogen isotopic ratios for the concentrator-induced mass-dependent fractionation. The ${ }^{20} \mathrm{Ne}$ concentration factor (relative to the bulk solar wind ${ }^{20} \mathrm{Ne}$ fluence) as a function of the radial distance from the concentrator target center can be used to deduce bulk solar wind fluences of elements between $\mathrm{He}$ and $\mathrm{Ne}$ measured in the concentrator target quadrants. We also performed high spatial resolution $\mathrm{Ne}$ measurements along all four arms of the concentrator gold cross and laboratory implantation experiments of noble gases into materials relevant to this work. The gold cross data revealed that the concentrator target was axially symmetrically irradiated, and major changes of the shape of the concentrator grids or misalignments of the assemblage during operation did not occur. The laboratory implantation experiments revealed that the SRIM-derived backscatter corrections agree well with measured data for implantation at angles of incidence of up to $45^{\circ}$ off normal, but somewhat underestimate backscatter loss at more shallow $\left(\geq 55^{\circ}\right)$ incidence, indicating that new backscatter corrections would need to be used in the concentrator ion simulation.

Acknowledgments - We thank NASA Discovery Mission Office for its support of the Genesis mission and the NASA Laboratory Analysis of Returned Samples Program Office for providing subsequent support. We greatly appreciate the support from Judith $\mathrm{H}$. Allton and the entire Genesis curation team at Johnson Space Center for sample selection. We are grateful to Yong Wang and the Los Alamos Ion Beam Materials Laboratory for performing the ion implants used in this work. We are very thankful for the comments and corrections provided by the referees Andrew Davis, Bernard Marty, Sasha Verchovsky and by the Associate Editor Marc Caffee. V. S. Heber acknowledges support 
by the Swiss National Science Foundation and NASA Cosmochemistry.

Editorial Handling-Dr. Marc Caffee

\section{REFERENCES}

Barraclough B. L., Dors E. E., Abeyta R. A., Alexander J. F., Ameduri F. P., Baldonado J. R., Bame S. J., Casey P. J., Dirks G., Everett D. T., Gosling J. T., Grace K. M., Guerrero D. R., Kolar J. D., Kroesche J. L. Jr., Lockhart W. L., McComas D. J., Mietz D. E., Roese J., Sanders J., Steinberg J. T., Tokar R. L., Urdiales C., and Wiens R. C. 2003. The plasma ion and electron instruments for the Genesis mission. Space Science Reviews 105:627-660.

Baur H. 1999. A noble-gas mass spectrometer compressor source with two orders of magnitude improvement in sensitivity (abstract). EOS Transactions of the American Geophysical Union, Supplement 46:F1118.

Burnett D. S., Barraclough B. L., Bennett R., Neugebauer M., Oldham L. P., Sasaki C. N., Sevilla D., Smith N., Stansbery E., Sweetnam D., and Wiens R. C. 2003. The Genesis discovery mission: Return of solar matter to Earth. Space Science Reviews 105:509-534.

Clayton R. N. 2003. Oxygen isotopes in meteorites. In Meteorites, comets, and planets, edited by Davis A. M. Treatise on Geochemistry, vol. 1. Amsterdam: Elsevier. pp. $129-142$.

Gloeckler G. and Geiss J. 2007. The composition of the solar wind in polar coronal holes. Space Science Reviews 130:139-152.

Hashizume K., Chaussidon M., Marty B., and Robert F. 2000. Solar wind record on the Moon: Deciphering presolar from planetary nitrogen. Science 290:1142-1145.

Heber V. S., Wiens R. C., Reisenfeld D. B., Allton J. H., Baur H., Burnett D. S., Olinger C. T., Wiechert U. H., and Wieler R. 2007. The Genesis solar wind concentrator target: Mass fractionation characterized by $\mathrm{Ne}$ isotopes. Space Science Reviews 130:309-316.

Heber V. S., Wieler R., Baur H., Olinger C. T., and Burnett D. S. 2009a. Noble gas composition of the solar wind as collected by the Genesis mission. Geochimica et Cosmochimica Acta 73:7414-7432.

Heber V. S., Wiens R. C., Bochsler P., Wieler R., and Burnett D. S. 2009b. Fractionation processes in the solar wind revealed by noble gases collected by Genesis regime targets (abstract \#2503). 40th Lunar and Planetary Science Conference. CD-ROM.

Heber V. S., Guan Y., Jurewicz A. J. G., Kallio A. P., Olinger C. T., Woolum D., McKeegan K. D., and Burnett D. S. 2010a. Solar wind elemental fractionation: Genesis C and $\mathrm{O}$ fluences by backside SIMS profiling-Preliminary data (abstract \#2234). 41st Lunar and Planetary Science Conference. CD-ROM.
Heber V. S., Wiens R. C., Vogel N., Baur H., Wieler R., McKeegan K. D., and Burnett D. S. 2010b. Genesis concentrator target: Isotopic and elemental fractionation of implanted solar wind characterized and quantified by $\mathrm{Ne}$ isotopes and the $\mathrm{Ne} / \mathrm{Ar}$ ratio in $\mathrm{SiC}$ (abstract \#1067). 41st Lunar and Planetary Science Conference. CD-ROM.

Jurewicz A. J. G., Burnett D. S., Wiens R. C., Friedmann T. A., Hays C. C., Hohlfelder R. J., Nishiizumi K., Stone J. A., Woolum D. S., Becker R. H., Butterworth A. L., Campbell A., Ebihara M., Franchi I. A., Heber V. S., Hohenberg C. M., Humayun M., McKeegan K. D., McNamara K., Meshik A. P., Pepin R. O., Schlutter D. J., and Wieler R. 2003. The Genesis solar-wind collector materials. Space Science Reviews 105:535-560.

Kallio A. P., McKeegan K. D., Jarzebinski G. J., Mao P. H., Kunihiro T., Coath C. D., Heber V. S., Burnett D. S., and Wiens R. C. 2010. Nitrogen isotopic composition of solar wind returned by the Genesis mission (abstract \#2481). 41st Lunar and Planetary Science Conference. CD-ROM.

Kerridge J. F. 1993. Long-term compositional variation in solar corpuscular radiation: Evidence from nitrogen in the lunar regolith. Reviews of Geophysics 31:423-437.

Marty B., Zimmermann L., Burnard P. G., Wieler R., Heber V. S., Burnett D. S., Wiens R. C., and Bochsler P. 2010. Nitrogen isotopes in the recent solar wind from the analysis of Genesis targets: Evidence for large scale isotope heterogeneity in the early solar system. Geochimica et Cosmochimica Acta 74:340-355.

McKeegan K. D., Kallio A. P., Heber V. S., Jarzebinski G. J., Mao P. H., Coath C. D., Kunihiro T., Wiens R. C., Allton J. H., and Burnett D. S. 2010. Genesis SiC concentrator sample traverse: Confirmation of ${ }^{16} \mathrm{O}$ depletion of terrestrial oxygen (abstract \#2589). 41st Lunar and Planetary Science Conference. CD-ROM.

Nordholt J. E., Wiens R. C., Abeyta R. A., Baldonado J. R., Burnett D. S., Casey P., Everett D. T., Kroesche J., Lockhart W. L., MacNeal P., McComas D. J., Mietz D. E., Moses R. W. Jr., Neugebauer M., Poths J., Reisenfeld D. B., Storms S. A., and Urdiales C. 2003. The Genesis solar wind concentrator. Space Science Reviews 105:561599.

von Steiger R., Schwadron N. A., Fisk L. A., Geiss J., Gloeckler G., Hefti S., Wilken B., Wimmer-Schweingruber R. F., and Zurbuchen T. H. 2000. Composition of quasistationary solar wind flows from Ulysses/Solar Wind Ion Composition Spectrometer. Journal of Geophysical Research 105:27217-27238.

Wiens R. C., Neugebauer M., Reisenfeld D. B., Moses R. W. Jr., Nordholt J. E., and Burnett D. S. 2003. Genesis solar wind concentrator: Computer simulations of performance under solar wind conditions. Space Science Reviews 105:601-625.

Ziegler J. F. 2004. SRIM-2003. Nuclear Instruments and Methods in Physics Research 219/220:1027-1036. 